\title{
The Economics of the Illicit Drugs-For-Guns Trade and Growth
}

\author{
King Yoong Lim* and Diego Morris**
}

April 14, 2020

\begin{abstract}
Ever since US president Richard Nixon declared a war on drugs in 1971, different drug control policies have been implemented in both consumer and producer countries. These include policies ranging from crop eradication to an interdiction of drug shipments to outright legalisation of drug possession. In this paper we develop a novel endogenous growth framework that unifies international trade, drugs control and accounts for consumers' rational addiction and optimizing choice of drug consumption. Our results emphatically show that a one size-fits-all approach to drug control is ineffective. We show that there exists a production -consumption growth trade-off around the policy priority not previously documented in the literature. Moreover, we show that in the absence of a fundamental change to drug demand, drug control policies are unlikely to reduce illicit trades for drugs and guns in the long run.
\end{abstract}

JEL Classification Numbers: E26, F59, O41, O54

Keywords: Central America, Economic Growth, Drugs, Illicit Trade, Organized Crime.

*Nottingham Business School, Nottingham Trent University, Email: king.lim@ntu.ac.uk; ${ }^{* *}$ Nottingham Business School, Nottingham Trent University, Email: diego.morris@ntu.ac.uk. Useful suggestions and comments from Alan Collins, Kwok Tong Soo, and colleagues in NTU are acknowledged. We also thank the Co-Editor and the two anonymous referees for useful comments provided. The views expressed are our own. 


\section{Introduction}

The link between illicit drugs, guns, and economic development is the subject of a long-standing debate about optimal substance abuse control strategies [see, for instance, Miron (2001), Demombynes (2011)]. Research in the U.S. has suggested that crime was prevalent around the period of the crack epidemic because the trade fueled demand for guns (Blumstein, 1995; Blumstein et al., 2000). ${ }^{1}$ Since Richard Nixon formally declared a war on drugs in 1971, different policies have been implemented in consumer, producer and transit countries (Whitford and Yates, 2009). These include policies ranging from crop eradication to an interdiction of drug shipments to outright legalization of drug possession. The results have been mixed, with the policy stance in several states and countries gradually shifting from prohibition to liberalization. The illicit drug trade, as well as its associated illicit trades in firearms, remains highly persistent, with activities by drug-related syndicates based in the Central American and Caribbean regions continuing to be a subject of frequent press coverage in the United States.

Against this backdrop, the general difficulties of doing research on illicit drug trades mean that, beyond primary fieldwork-based research, there remains a vacuum in terms of the existing body of evidence on the macroeconomics of drugs, with studies of consumers and the drugs supply chain tending to be largely separate. In fact, although a tough policy stance remains the general consensus, there are some researchers who have argued that aggressive drug enforcement is not only ineffective but also potentially amplifies crime. $^{2}$ For instance, Becker et al. (2006) note that if the demand for drugs is inelastic, increased enforcement will increase the price and reduce consumption, but it will also increase the total resources available to drug syndicates. Likewise, in Ortiz (2003, 2009),

\footnotetext{
${ }^{1}$ In its report, the Latin American Commission on Drugs and Democracy (2016) highlighted this linkage: "the relationship between homicide, firearm, and drug commerce is central. Drugs finance the purchase of firearms, which in turn are used as indirect factors of drugs production and trafficking."

${ }^{2}$ There has also been experiments with greater liberalization of drug policy. As an example, the authorities in Portugal decriminalized the use of all drugs in 2001 and unleashed a major public health campaign to tackle addiction.
} 
drug policy ineffectiveness is due to drug producers responding by improving productivity to compensate for the increased repression. Under these conditions, facing robust revenue, drug syndicates are better equipped to further purchase weapons to aid their illicit trades. ${ }^{3}$

To date, the applied-theory literature on the macroeconomics of illicit drugs is very small (some exceptions are: Rydell et al., 1996; Becker et al., 2006; Naranjo, 2007; Grossman and Mejía, 2008; Costa Storti and De Grauwe, 2009; Ortiz, 2009; Chumacero, 2010; Mejía and Restrepo, 2011; Mejía and Restrepo, 2016; Greenfield et al., 2017). Unfortunately, these papers have all focused on partial equilibrium analysis or the vertical supply-chain of illicit drugs. For instance, Caulkins et al. (2001) and Rydell et al. (1996) use a partial equilibrium approach to study the policy trade-off between treatment and enforcement policies in reducing the consumption of illegal drugs. They show that spending on treatment and enforcement should vary as the size of the problem. Specifically, they show that treatment should receive a larger share of control resources when a drug problem is mature than when it is first growing. If initiation rates subsequently decline, enforcement's budget share should drop further in the ensuing declining stage of the epidemic. Similarly, Grossman and Mejía (2008) study the relative efficiency and effectiveness of eradication and interdiction efforts in a partial equilibrium game theory model. They show that from 2001 through 2003 subsidies from the United States to the Colombian armed forces under Plan Colombia caused a decrease in the exportation of drugs from Colombia to about $44 \%$ of what exportation was before Plan Colombia was implemented. Notwithstanding, the benefits in the U.S. in terms of drug addiction was not commensurate.

Nevertheless, the market for illegal drugs hides complex interactions that should be addressed using models that can account for general equilibrium effects, especially when evaluating large-scale policy interventions. Some recent papers incorporating these

\footnotetext{
${ }^{3}$ Evidence for this hypothesis comes from a long-term look at the evolution of crime rate in the U.S.: Dills et al. (2010) show that increases in enforcement of drug prohibition in the U.S. over the past 100 years have been associated with increases in crime rate.
} 
effects include Becker et al. (2006), Naranjo (2007), Costa Storti and De Grauwe (2009), Chumacero (2010), Mejía and Restrepo (2011) and Mejía and Restrepo (2016). We expand the literature by adopting a horizontal perspective to model the illicit drugs and guns trade. This allows us to develop a unified endogenous growth framework with international trade and drugs control that also accounts for consumers' rational addiction and optimizing choice of drug consumption.

In this vein, to date, research has been missing a unified growth framework that includes the integration of formal international trade and illicit drug-for-gun trade, as well as different drugs control policies aimed at consumers, producers and intermediate trans-shipments. Our paper aims to address this by developing a two-country, endogenous growth framework with international and illicit drug-for-gun trades. Specifically, we build a two-country, multi-sectorial dynamic general equilibrium model of endogenous growth with drugs and guns trade that is solved both analytically and computationally. The parameterized version, an illustrative 'source' economy based on five regional developing economies (El Salvador, Guatemala, Honduras, Jamaica, and Mexico) that are controversially known as 'nest' of illicit drugs and guns trade to/from the U.S., is then used to study various drug-control policies. As shown in Figure 1 and 2, the context of our analysis is supported by cross-country evidence. Drug usage, proxied by annual prevalence rate from the UNODC drug statistics and the rate of civilian-held firearms using data from the 2017 Small Arms Survey are both positively correlated with GDP per capita (about 38\%). Similarly, the rate of civilian-held firearms and drugs are also significantly positively correlated (31\%).

To preview our results, while prohibitive drug-control policy (both at the end-consumer and supply side) is trade- and growth-enhancing to the formal sector, we uncover a production-consumption growth trade-off that has not been previously documented in the literature. Hence, if private consumption growth is prioritized in the consuming country over output growth, there is rationale for drug liberalization. Indeed, 
the policy effect is nonlinear in that, the more open the consuming country is (a larger share of imported tradables in final consumption), the wider the range of initial rational-addiction condition that would allow drug liberalization policy to be growth-enhancing. In addition, in the absence of any fundamental change to drug demand, our policy experiments find that drug control policies is unlikely to reduce illicit trades for drugs and guns in the long run. A more direct supply-side policy aimed at eradicating drug cultivation appears to be less effective, and its effectiveness would depend a lot on the openness of the supplying country. We believe some of these findings provide partial explanation on the mixed outcome observed from the global war on drugs over the past few decades.

The rest of the paper are structured as follows. Section 2 describes the theoretical model. Section 3 defines the dynamic and balanced growth equilibrium, and then proceeds to solve the model. In Section 4, the parameterization strategy is discussed. The various illustrative drug-control policy experiments, structured according to different policy themes, are presented in Section 5. Section 6 concludes the paper.

\section{The Model}

We present a two-country dynamic general equilibrium model with international trade. Country A is a 'physical capital-rich' developed economy populated by a representative household who consumes ordinary tradable goods (domestically produced and traded from Country B) and drugs - the latter modelled as a rationally addicted good that is not produced in Country A. Firms in Country A produces ordinary tradable goods using labor and physical capital. There is also a price-taking firm producing guns, using a proprietary technology and inputs of domestically produced ordinary tradables. ${ }^{4}$ Due

\footnotetext{
${ }^{4}$ Alternatively, one can argue that the production of guns requires the use of physical capital. Given that the ordinary tradables produced in Country A have already used both labor and physical capital as inputs, specifying guns as being a transformation of ordinary tradables would have the same
} 
to legal restriction, the guns produced are not sold to the household, but exported to Country B and purchased by the Government in Country A. The Government taxes labor and capital income, as well as the sales of guns. Although the Government can discourage drugs by influencing the overall climate for drug consumption, it is not deemed as a criminal offense.

Country B is a 'physical capital-poor' developing economy that is trade-dependent to Country A. It is populated by identical individuals and a drug syndicate. Individuals do not hold physical capital, consume ordinary tradables (domestically produced and traded from Country A), and do not consume drugs. Instead, they supply labor hours to both a representative firm in the formal sector producing ordinary tradables, as well as a drug syndicate who produces drugs. Both production activities in Country B are human capital-driven (similar to Mocan et al., 2005), with the individuals having a choice to invest in formal human capital but not drug-specific human capital. The drug syndicate is modelled as a stylized agent similar in fashion to Blackburn et al. (2017) and related studies $^{5}$, who maximizes its expected payoff by producing drugs using effective labor hours and guns imported from Country A (in line with the time series evidence of Millán-Quijano, 2019, who shows a positive cocaine prices-crime relationship in supplier countries). The drug syndicate's productivity depends on the average level of drug-specific human capital (interpretable as some sort of cultural capital), which in equilibrium, equals to the accumulated stock of drugs addiction in Country A. This means that the growth of the illicit human capital over time, which cannot be accumulated via deliberate acquisition of education, would reflect the overall magnitude of the illicit trade (proxied by its accumulated flows over time). This is similar to the concept of a "standing on shoulder" effect for knowledge/ideas (Jones, 2005), where the

interpretation. Instead, productivity of guns-production benefits from an Arrow-Romer type of knowledge spillover embedded in the physical capital stock in Country A.

${ }^{5}$ In practice, organized drug syndicates tend to have much more sophisticated structure, as documented in contributions such as Levitt and Venkatesh (2000) and similar case studies. In a two-country, multi-sectorial general equilibrium framework, some of these features are abbreviated. 
level of illicit human capital would reflect all the learnings from/associated with all the past accumulated drug production.

Our specification for Country B essentially 'merges' the production chains of illicit-crop farming and drug trafficking into a single drug syndicate, as compared to the vertically-integrated model of Mejía and Restrepo (2016). Nevertheless, given that most mechanisms (in the different vertical production chains) in their model operate through resource (re-)allocation, the differences - in terms of transmission mechanisms - of our simplified specification for Country B are largely immaterial in a long-run context. Instead, we trade some of the vertical features off for a greater horizontal perspective on the illicit drugs and guns trades, by developing a two-country, multi-sectorial dynamic general equilibrium framework, hence allowing for the examination of dynamic tradeoff and long-run growth implications of drug-control policies. Overall, the assumed asymmetries between the two countries are by design, and capture the differences between a physical capital-intensive, "richer" economy and a physical capital-inadequate, "poorer" economy whose formal sector is trade-dependent to the larger consumer country, with its best option out of a "drug-cultivation trap" will be through a reallocation away of human capital from the drug-producing to the formal sectors, as argued in LSE (2014).

\subsection{Country A}

Country A Household: The representative household in Country A faces a risk neutral expected lifetime utility, which depends on the chosen sequences of consumption

of ordinary tradable goods (a bundle of tradable home good and imported good), $C_{t+s}$, labor, $L_{t+s}$, and the consumption of drugs, $\xi_{t+s}$, for $s=0,1, \ldots, \infty$, as in

$$
U_{t}=\mathbb{E}_{t} \sum_{s=0}^{\infty} \Lambda^{s}\left(\frac{\left(C_{t+s}^{A}\right)^{1-\varsigma_{C A}^{-1}}}{1-\varsigma_{C A}^{-1}}-\frac{\eta_{L}}{1+\psi} L_{t+s}^{1+\psi}+\pi \frac{\left[\xi_{t+s}\left(\Xi_{t+s}\right)^{\eta_{\Xi}}\right]^{1-\varsigma_{\Xi}^{-1}}}{1-\varsigma_{\Xi}^{-1}}\right)
$$


where $C_{t}^{A}$ is an aggregate index of consumption, $\varsigma_{C A}>0$ intertemporal elasticity of substitution in consumption, $L_{t}=\int_{0}^{1} L_{t}^{i} d i=L_{t}^{T, A}$, the share of total time endowment (normalized to unity) spent working, with $L_{t}^{i}$ denoting the raw labor hours provided to the $i$ firms, $\Lambda \in(0,1)$ the subjective discount factor, $\Xi_{t}$ is the period $t$ stock of accumulated past drugs consumption taken as given by household, $\mathbb{E}_{t}$ the expectation operator conditional on the information available at the beginning of period $t$. Instantaneous utility is therefore additively separable in terms of the consumption of ordinary tradable goods and drugs. ${ }^{6}$

In each period $t$, the utility derived from drugs consumption depends on an overall climate factor, which, for convenience, assumed to be an exogenously given value, $\pi$, uniformly distributed on the support $(0,1]$. To avoid corner solution, $\pi>0$, so that the household always derives positive utility from rational addiction. This simple specification can be interpretable as a continuous measure of how likely the possession of drugs is acceptable in society and therefore avoid confiscation and punishment by the government. As such, addiction is not state-dependent, and that drug possession is assumed to be not a criminal offense. ${ }^{7}$ Further, in line with the tradition of Becker and Murphy (1988), we assume addiction is both time-consistent and rational, and the utility generated from drugs consumption depends on both current and past accumulated consumption. ${ }^{8}$ Specifically, the stock of past consumption, $\Xi_{t}$, is specified to evolve according to $\Xi_{t+1}=(1-\phi) \Xi_{t}+\xi_{t}$, or equivalently,

\footnotetext{
${ }^{6}$ In spite of the additive separable functional form, current-period drug consumption $\left(\xi_{t}\right)$ is quasi-complementary to past accumulated consumption $\left(\Xi_{t}\right)$, a key feature that is consistent with the rational addiction literature in the tradition of Becker and Murphy (1988), with relatively more sophisticated utility specification of rational addiction further discussed in Orphanides and Zervos (1995), Gruber and Köszegi (2001).

${ }^{7}$ While debatable, the simplification in assuming drug as not a imprisonable offense is in line with empirical evidence such as Kuziemko and Levitt (2004), which documented that the overall impact of increased drug incarceration has been very small in reducing the criminal incidence.

${ }^{8}$ In microeconomic studies focusing on cigarettes' addiction, such as Gruber and Koszegi (2001), agents with time-inconsistent optimization problem are considered. They also consider the self-control problem of a sophisticated agent, whose consumption decision is modelled as a subgame-perfect equilibrium in a dynamic game played by the successive intertemporal selves. These are not considered here.
} 


$$
\frac{\Xi_{t+1}}{\Xi_{t}}=(1-\phi)+\frac{\xi_{t}}{\Xi_{t}}
$$

where $\phi \in[0,1]$ measures the degree of persistence of addiction from accumulated past consumption of drugs. If $\phi=0$, past addiction does not diminish over time, while $\phi=1$ means drugs consumptions in the past do not influence the accumulation/addiction process.

In addition to labor supply (although raw labor hours are chosen, household is remunerated $w_{t}^{T, A}$ based on effective hours, which in turn depends on productivity that is affected by drug consumption), household also owns and supplies physical capital at each period $t$, the income of which taxed at constant rates, $\tau_{L}$ and $\tau_{K}$, respectively. Similar to studies with tradable goods framework, such as Agénor (2016), consumption decisions on ordinary tradable goods follow a two-step process: first, the optimal path of total consumption over time is determined, the amount from which is then allocated between spending on domestic and foreign tradables. The representative household maximizes (1) by choosing the optimal sequences of ordinary tradable consumption, $C_{t}^{A}$, labor, $L_{t}^{T, A}$, drugs consumption, $\xi_{t}$, and the physical capital stock in the next period, $K_{t+1}$, subject to the end-of-period budget constraint,

$$
\left(1-\tau_{L}\right) w_{t}^{T, A} A_{t}^{T, A} L_{t}^{T, A}+\left(1-\tau_{K}\right) r_{t}^{T, A} K_{t}=P_{t}^{T}\left(C_{t}^{A}+I_{t}\right)+P_{t}^{\xi} \xi_{t}
$$

where

$$
K_{t+1}=\left(1-\delta^{K}\right) K_{t}+I_{t}
$$

taking wages $\left(w_{t}^{T, A}\right)$, labor productivity $\left(A_{t}^{T, A}\right)$, real interest rate $\left(r_{t}^{T, A}\right)$, tax rates, price of tradable goods $\left(P_{t}^{T}\right)$, and price of drugs $\left(P_{t}^{\xi}\right)$ as given.

In Appendix A, we derive the following first-order conditions:

$$
\frac{\mathbb{E}_{t} C_{t+1}^{A}}{C_{t}^{A}}=\left\{\frac{1}{\Lambda} \frac{\mathbb{E}_{t} P_{t+1}^{T}}{P_{t}^{T}}\left[\left(1-\tau_{K}\right) \mathbb{E}_{t} r_{t+1}^{T, A}+\left(1-\delta_{K}\right)\right]\right\}^{-\varsigma_{C A}}
$$




$$
\begin{gathered}
\frac{\mathbb{E}_{t} \xi_{t+1}}{\xi_{t}}=\left\{\frac{1}{\Lambda}\left(\frac{\mathbb{E}_{t} \Xi_{t+1}}{\Xi_{t}}\right)^{\frac{{ }_{\Xi}}{\eta_{\Xi}\left(\Xi^{-1)}\right.}} \frac{\mathbb{E}_{t} P_{t+1}^{\xi}}{P_{t}^{\xi}}\left[\left(1-\tau_{K}\right) \mathbb{E}_{t} r_{t+1}^{T, A}+\left(1-\delta_{K}\right)\right]\right\}^{-\varsigma \Xi}, \\
\eta_{L} L_{t}^{\psi}=\frac{\left(C_{t}^{A}\right)^{-\varsigma_{C A}^{-1}}}{P_{t}^{T}}\left(1-\tau_{L}\right) w_{t}^{T, A} A_{t}^{T, A} . \\
P_{t}^{\xi}=\pi\left(\Xi_{t}\right)^{\eta_{\Xi}\left(1-\varsigma_{\Xi}^{-1}\right)} \xi_{t}^{-\varsigma_{\Xi}^{-1}}\left(1-\tau_{L}\right) \frac{w_{t}^{T, A} A_{t}^{T, A}}{\eta_{L} L_{t}^{\psi}} .
\end{gathered}
$$

Equation (5) is the Euler equation associated with ordinary consumption; equation (6) is the corresponding version for drug consumption (which depends on the growth of the total stock of past consumption, $\Xi_{t+1} / \Xi_{t}$, given by (2); equation ( 7 ) describes the marginal rate of substitution between labor supply and ordinary tradable consumption; (8) is the optimality condition for the marginal rate of substitution between drugs consumption and labor supply.

Combining (7) and (8), the ordinary-drugs consumption ratio of the representative household is given by

$$
\frac{C_{t}^{A}}{\xi_{t}}=\pi^{-\varsigma_{C A}}\left(\Xi_{t}\right)^{\frac{\varsigma_{C A}}{\varsigma_{\Xi}}\left[\eta_{\Xi}\left(1-\varsigma_{\Xi}\right)+1\right]}\left(\frac{\xi_{t}}{\Xi_{t}}\right)^{\frac{\varsigma_{C A}}{\varsigma_{\Xi}}}\left(\frac{P_{t}^{\xi}}{P_{t}^{T}}\right)^{\varsigma_{C A}},
$$

which depends on the accumulated stock of past drugs consumption, and the relative market price ratio of the two "goods". To ensure stationarity on the balanced growth path, it is assumed that $\varsigma_{C A}\left[\eta_{\Xi}\left(1-\varsigma_{\Xi}\right)+1\right] / \varsigma_{\Xi}=0$.

Nominal consumption spending on non-addictive, ordinary tradable goods is $P_{t}^{T}\left(C_{t}^{A, A}+C_{t}^{A, B}\right)$, where $C_{t}^{A, A}$ is consumption of ordinary tradables home good and $C_{t}^{A, B}$ the imported tradables from Country B. Total consumption is therefore a bundle,

$$
C_{t}^{A}=\left(C_{t}^{A, A}\right)^{\theta}\left(C_{t}^{A, B}\right)^{1-\theta}
$$

where $\theta \in(0,1)$. The second stage of the optimization problem for the representative household is therefore to maximize (10) subject to a static budget constraint of $P_{t}^{T} C_{t}^{A}=$ $P_{t}^{T} C_{t}^{A, A}+P_{t}^{T} C_{t}^{A, B}$, which yields an optimal consumption allocation between Country A's 
$\left(C_{t}^{A, A}\right)$ and Country B's tradables $\left(C_{t}^{A, B}\right)$ for the household in Country A:

$$
\frac{C_{t}^{A, B}}{C_{t}^{A, A}}=\frac{1-\theta}{\theta}
$$

Country A Production: The tradable goods are produced by a continuum of identical perfectly competitive firms $i \in(0,1)$, using effective labor, $A_{t}^{T, A} L_{t}^{i, T, A}$, and private physical capital, $K_{t}^{i, A}$. The production function of firm $i$ is given by

$$
Y_{t}^{i, T, A}=Q_{t}^{i, T, A}\left(A_{t}^{T, A} L_{t}^{i, T, A}\right)^{\beta}\left(K_{t}^{i, A}\right)^{1-\beta}
$$

where the productivity of firms $i, Q_{t}^{i, T, A}$, evolves according to the sectorial-wide physical capital intensity. Specifically, productivity of firm $i$ is subject to a sector-wide Arrow-Romer type of externality, congested by the total employment in the sector (in raw terms), as in

$$
Q_{t}^{i, T, A}=Q_{0}^{T, A}\left[\frac{K_{t}^{A}}{L_{t}^{T, A}}\right]^{\varpi_{T}}
$$

where $K_{t}^{A}=\int_{0}^{1} K_{t}^{i, A} d i, \varpi_{T}>0$.

The profit maximization problem for each firm $i$ involves maximizing

$$
\Pi_{t}^{i, T, A}=P_{t}^{T} Y_{t}^{i, T, A}-w_{t}^{T, A}\left(A_{t}^{T, A} L_{t}^{i, T, A}\right)-r_{t}^{T, A} K_{t}^{i, A}
$$

with respect to the private inputs, taking production function, productivity, and input prices as given. This yields:

$$
A_{t}^{T, A} w_{t}^{T, A}=\frac{\beta P_{t}^{T} Y_{t}^{i, T, A}}{L_{t}^{i, T, A}}, \quad r_{t}^{T, A}=(1-\beta) \frac{P_{t}^{T} Y_{t}^{i, T, A}}{K_{t}^{i, A}} .
$$

In a symmetric equilibrium, given that all firms are identical, we have $Q_{t}^{T, A}=Q_{t}^{i, T, A}$, $K_{t}^{A}=K_{t}^{i, A}$, and $Y_{t}^{T, A}=Y_{t}^{i, T, A} \forall i$, which yields the aggregate tradable output produced in Country A: 


$$
Y_{t}^{T, A}=\int_{0}^{1} Y_{t}^{i, T, A} d i=Q_{t}^{T, A}\left(A_{t}^{T, A} L_{t}^{T, A}\right)^{\beta}\left(K_{t}^{A}\right)^{1-\beta},
$$

or equivalently, after substituting in (13),

$$
Y_{t}^{T, A}=Q_{0}^{T, A}\left(A_{t}^{T, A}\right)^{\beta}\left(L_{t}^{T, A}\right)^{\beta-\varpi_{T}}\left(K_{t}^{A}\right)^{1-\beta+\varpi_{T}} .
$$

Further, the labor productivity level, $A_{t}^{T, A}$, is specified as influenced by drugs consumption, as in

$$
A_{t}^{T, A}=A_{0}^{A}\left(\frac{\xi_{t}}{\Xi_{t}}\right)^{v_{A}}
$$

where $A_{0}^{A}>0$, and $v_{A} \in \mathbb{R}$ measures the strength of the drugs' effects on labor productivity. $v_{A}$ is parameterized as a negative value for benchmark case to account for the adverse effect of drugs consumption on labor productivity. The current-period drug consumption is scaled by the accumulated drug consumption $\left(\Xi_{t}\right)$ to provide a scale adjustment so that the effective contemporaneous effect of drug consumption to labor productivity depends also on how prevalent drug consumption is. If it is already prevalent, then an existing labor who is already used to drug consumption will experience less negative effect than a labor who has never experienced drug before.

Substituting (17) into (16), we can write

$$
Y_{t}^{T, A}=Q_{0}^{T, A}\left(A_{0}^{A}\right)^{\beta}\left(\frac{\xi_{t}}{\Xi_{t}}\right)^{v_{A} \beta}\left(L_{t}^{T, A}\right)^{\beta-\varpi_{T}}\left(K_{t}^{A}\right)^{1-\beta+\varpi_{T}}
$$

Likewise, using the two first-order conditions in (14), we derive a ratio of the factor prices in Country A as

$$
\frac{w_{t}^{T, A}}{r_{t}^{T, A}}=\frac{\beta}{1-\beta} \frac{K_{t}^{A}}{L_{t}^{T, A}} \frac{1}{A_{t}^{T, A}},
$$

or equivalently, by substituting in (17),

$$
\frac{w_{t}^{T, A}}{r_{t}^{T, A}}=\frac{\beta}{1-\beta} \frac{K_{t}^{A}}{L_{t}^{T, A}}\left(A_{0}^{A}\right)^{-1}\left(\frac{\xi_{t}}{\Xi_{t}}\right)^{-v_{A}} .
$$


Assumption: $\beta=\varpi_{T}$. To derive endogenous growth, we restrict our analysis by imposing the assumption, which then allows us to write (18) as a ratio of the ordinary tradables to physical capital in Country A:

$$
\frac{Y_{t}^{T, A}}{K_{t}^{A}}=Q_{0}^{T, A}\left(A_{0}^{A}\right)^{\beta}\left(\frac{\xi_{t}}{\Xi_{t}}\right)^{v_{A} \beta} .
$$

Guns production: Due to legal restriction, guns are produced by a single firm in Country A. The production of guns is taxed by the government at a constant rate of $\tau_{G}$. Guns are not sold to households. Instead, guns are exported to Country B and sold to the Government for Country A. The price of guns, $P_{t}^{G}$, is set by the world market (given the two-country context, this means the demand of buyers from Country B), with the purchase of the Government for Country A following the same world price. ${ }^{9}$ The guns-producing firm has a proprietary production technology of

$$
Y_{t}^{G, A}=A_{t}^{G}\left(Y_{t}^{T, A G}\right)^{\chi}
$$

where $\chi \geq 0, Y_{t}^{T, A G}$ is the quantity of ordinary tradables used in guns' production, and $A_{t}^{G}$ is a productivity parameter given by $A_{t}^{G}=A_{0}^{G}\left(K_{t}^{A}\right)^{\omega}$, where similar to ordinary tradable production, the productivity of the firm benefits from knowledge spillover embedded in the aggregate physical capital stock of the economy, at a rate $\omega>0$.

Given the tax rate and the perfectly competitive market for physical capital, the profit maximization problem for the guns-producing firm is simply given by the unconstrained maximization problem of:

$$
\max _{Y_{t}^{T, A G}}\left(1-\tau_{G}\right) P_{t}^{G} Y_{t}^{G, A}-P_{t}^{T} Y_{t}^{T, A G}
$$

\footnotetext{
${ }^{9}$ With this specification, we essentially treats all illicit component of world gun trades as the exported share, while the purchase made by the government in Country A is interpreted as all other legal purchases. As such, given that the government has imperfect information on the international buyer of guns, it is reasonable to levy any tax rate of guns at the production stage, and not sales stage.
} 
with $Y_{t}^{G, A}$ given by (21), which yields the first-order condition for the demand of ordinary tradables in gun-production

$$
Y_{t}^{T, A G}=\left[\frac{\left(1-\tau_{G}\right) P_{t}^{G} A_{0}^{G} \chi}{P_{t}^{T}}\right]^{\frac{1}{1-\chi}}\left(K_{t}^{A}\right)^{\frac{\omega}{1-\chi}} .
$$

Assumption: $\omega=1-\chi$. Again, to get endogenous growth, we restrict our analysis by imposing the assumption to rewrite (22) in the AK-form of

$$
\frac{Y_{t}^{T, A G}}{K_{t}^{A}}=\left[\left(1-\tau_{G}\right) A_{0}^{G} \chi\right]^{\frac{1}{1-\chi}}\left(\frac{P_{t}^{G}}{P_{t}^{T}}\right)^{\frac{1}{1-\chi}} .
$$

Government of Country A: The government in Country A does not borrow and maintains a balanced budget in each period $t$. The government collects taxed income from the labor and physical capital, as well as from total guns production $\left(P_{t}^{G} Y_{t}^{G, A}\right)$. The government spends on consumption of domestically produced ordinary tradables $\left(G_{t}^{A}\right)$, guns produced in Country $\mathrm{A}\left(G_{t}^{G}\right)$. In addition, the government gets realizable value from confiscated drugs in each period, $R_{t}$. For simplicity, we assume that the rebate is a very small fraction, $z \in(0,1)$ of the confiscated drugs:

$$
R_{t}=z(1-\pi) P_{t}^{\xi} \xi_{t}
$$

The budget constraint of the government is therefore given by

$$
\tau_{L} w_{t}^{T, A} A_{t}^{T, A} L_{t}^{T, A}+\tau_{K} r_{t}^{T, A} K_{t}+\tau_{G} P_{t}^{G} Y_{t}^{G, A}+R_{t}=P_{t}^{T} G_{t}^{A}+P_{t}^{G} G_{t}^{G} .
$$

Without losing generality, government consumption of the ordinary tradables is assumed to be a fixed fraction of the domestic households' consumption,

$$
G_{t}^{A}=\nu C_{t}^{A, A}, \nu \in(0,1)
$$

\subsection{Country B}

Country B Individuals: In Country B, there is a unit mass of identical individuals $j \in(0,1)$. Each individual $j$ is endowed with one unit of time in each period $t$, and 
for simplicity, individuals do not value leisure in Country B and time is fully allocated to between working in the tradable sector and working for the drug syndicate, in that $L_{j, t}^{T, B}+L_{j, t}^{\xi, B}=L_{j, t}^{B}$, where $L_{j, t}^{B}=1$. Nevertheless, individuals do face some degree of disutility from working, interpretable as due to poor working conditions. Individuals in Country B consume ordinary tradables and are assumed to not consume drugs. Wage income is paid to effective labor in both sectors in that it is influenced by the level of human capital/productivity, though individuals can only invest in formal human capital. In other words, investment in the level of formal human capital that is useful in ordinary tradable production, $H_{j, t}^{T, B}$, is a choice variable. Each individual $j$ therefore chooses a sequence of investment, $I_{j, t+s}^{T, B}$ (in tradable price), total consumption, $C_{j, t+s}^{B}$, the labor hours supplied to both ordinary tradable sector $\left(L_{j, t+s}^{T, B}\right)$ and the drug syndicate $\left(L_{j, t+s}^{\xi, B}\right)$, for $s=0,1, \ldots, \infty$, to maximize expected utility,

$$
\max V_{t}^{j}=\mathbb{E}_{t} \sum_{s=0}^{\infty} \Lambda^{s}\left[\frac{\left(C_{j, t+s}^{B}\right)^{1-\varsigma_{C B}^{-1}}}{1-\varsigma_{C B}^{-1}}-\frac{\eta_{B}}{1+\psi_{B}}\left(L_{j, t}^{T, B}+L_{j, t}^{\xi, B}\right)^{1+\psi_{B}}\right],
$$

where $\Lambda \in(0,1)$ the common subjective discount factor, $\varsigma_{C B}>0$ intertemporal elasticity of substitution in consumption, and $\eta_{B}>0$, subject to end-of-period budget constraint:

$$
w_{t}^{T, B} H_{j, t}^{T, B} L_{j, t}^{T, B}+w_{t}^{\xi, B} H_{j, t}^{\xi, B} L_{j, t}^{\xi, B}+\xi_{j} J_{t}^{T, B}=P_{t}^{T}\left(C_{j, t}^{B}+I_{j, t}^{T, B}\right),
$$

and the time constraint $L_{j, t}^{T, B}+L_{j, t}^{\xi, B}=1$, taking the profits received from owning the representative firm, $J_{t}^{T B}\left[\xi_{j} \in(0,1)\right.$ being the fraction of the profits claimed by individual $j]$, the respective real wage for employment in the ordinary tradable and drugs production sector, $w_{t}^{T, B}$ and $w_{t}^{\xi, B}$, the average drug-specific productivity level, $H_{j, t}^{\xi, B}$, and the tradable price, $P_{t}^{T}$, as given.

The human capital of individual $j$ evolves according to

$$
H_{j, t+1}^{T, B}=\Theta_{H B} I_{j, t}^{T, B}+\left(1-\delta^{H B}\right) H_{j, t}^{T, B}
$$

where $\Theta_{H B}>0$ is the efficiency of human capital investment and $\delta^{H B} \geq 0$ is the 
depreciation rate of human capital.

Solving an individual $j$ 's optimization problem yields the first-order conditions:

$$
\begin{gathered}
\left(\frac{\mathbb{E}_{t} C_{j, t+1}^{B}}{C_{j, t}^{B}}\right)^{\varsigma_{C B}^{-1}}=\Lambda\left[\frac{\Theta_{H B} w_{t+1}^{T, B} H_{j, t+1}^{T, B}}{P_{t+1}^{T}}+\left(1-\delta^{H B}\right)\right] \\
L_{j, t}^{T, B}+L_{j, t}^{\xi, B}=\left[\frac{\left(C_{j, t}^{B}\right)^{-\varsigma_{C B}^{-1}}}{P_{t}^{T} \eta_{B}} w_{t}^{T, B} H_{j, t}^{T, B}\right]^{1 / \psi_{B}}, \\
H_{j, t}^{T, B} w_{t}^{T, B}=H_{t}^{\xi, B} w_{t}^{\xi, B}
\end{gathered}
$$

Consumption decisions follow a two-step process too. Let $C_{j, t}^{B, B}$ is consumption of ordinary tradables home good and $C_{j, t}^{B, A}$ the imported tradables from Country A. Total consumption of each individual $j$ in Country B is therefore a bundle,

$$
C_{j, t}^{B}=\left(C_{j, t}^{B, B}\right)^{\varrho}\left(C_{j, t}^{B, A}\right)^{1-\varrho}
$$

where $\varrho \in(0,1)$. The second stage of the optimization problem for each individual $j$ is therefore to maximize (33) subject to a static budget constraint of $P_{t}^{T} C_{t}^{B}=P_{t}^{T} C_{t}^{B, B}+$ $P_{t}^{T} C_{t}^{B, A}$, which yields an optimal consumption allocation of:

$$
\frac{C_{t}^{B, A}}{C_{t}^{B, B}}=\frac{1-\varrho}{\varrho} .
$$

Country B production: The tradable goods are produced by a price-taking representative firm using only labor. The production technology is decreasing returns-to-scale and given by

$$
Y_{t}^{T, B}=Q_{t}^{T, B}\left(H_{t}^{T, B} L_{t}^{T, B}\right)^{\alpha}
$$

where $\alpha \in(0,1), H_{t}^{T, B}$ and $L_{t}^{T, B}$ are the average human capital level and total labor hours employed in the tradable sector.

Productivity of the ordinary tradables-producing firm in Country $\mathrm{B}, Q_{t}^{T, B}$, is assumed 
to depend linearly on a scale factor from its trading partner, proxied by the ordinary tradable output-to-physical capital ratio of Country A, as well as a knowledge spillover effect from the (aggregate) stock of formal human capital in Country B, at a magnitude $\phi_{1} \geq 0$. Specifically,

$$
Q_{t}^{T, B}=Q_{0}^{B}\left(H_{t}^{T, B}\right)^{\phi_{1}} \frac{Y_{t}^{T, A}}{K_{t}^{A}} .
$$

As would become clear in the policy experiments section later, this specification means growth in Country B's tradable production can only be driven by growth in $H_{t}^{T, B}$ [indirectly, policy parameters in (29)] in the steady state, as any other change in policy arrangements will be growth-neutral and only bring about level effect on tradable production in Country B. The rationale underlying this deliberate choice is twofold: (i) to reflect the historical trade and production dependency of the small Central American economies (Country B) to the large consumer economy (USA), which means any productivity gain over time must therefore be from the learning/knowledge spillover from the production in Country A; and (ii) to capture some of the well-documented persistency in the mediocre growth rates observed in many source countries for drugs cultivation [see LSE (2014) and Buxton (2015)].

Solving the firm's profit maximization problem, $\max _{L_{t}^{T, B}} \pi_{t}^{T, B}=P_{t}^{T} Y_{t}^{T, B}-w_{t}^{T, B} H_{t}^{T, B} L_{t}^{T, B}$, yields the first-order condition of

$$
\frac{\alpha P_{t}^{T} Y_{t}^{T, B}}{L_{t}^{T, B}}=w_{t}^{T, B} H_{t}^{T, B} .
$$

Given that individuals are identical, we know that the average and individual-specific productivity level in the economy is the same, $H_{t}^{T, B}=H_{j, t}^{T, B}$.

Assumption: $\phi_{1}+\alpha=1$. To eventually generate endogenous growth for the ordinary tradable output in Country B, we impose the assumption and rewrite (35) as 


$$
\frac{Y_{t}^{T, B}}{H_{t}^{T, B}}=Q_{0}^{B} \frac{Y_{t}^{T, A}}{K_{t}^{A}}\left(L_{t}^{T, B}\right)^{\alpha} .
$$

Drug Syndicate: Similar to Blackburn et al. (2017) and other similar studies in the literature of organized crime, such as Alexeev et al. (2004) and Kugler et al. (2005), the drugs sector is modelled as an independent entity from the households in Country B. In other words, the crime syndicate is modelled as a rational decision maker whose sole objective is to maximize its expected payoff from producing drugs, $E\left(v_{t}^{\xi}\right)$. For simplicity, we assume the crime syndicate does not consume ordinary tradables. The drugs' production technology is given by

$$
\xi_{t}=A_{0}^{R}\left(H_{t}^{\xi, B} L_{t}^{\xi, B}\right)^{\varphi}\left(G_{t}^{F}\right)^{1-\varphi}
$$

where $\varphi \in(0,1)$, and $A_{0}^{R}>0$ is a time-invariant constant productivity level of the drugs-producer. $H_{t}^{\xi, B} L_{t}^{\xi, B}$ is the effective labor hours used in producing drugs, with a one-to-one relationship assumed between drug-specific human capital (which is akin to a type of cultural capital that is common across all workers working in drugs production) and the total accumulated world drugs consumption, in that, $H_{t}^{\xi, B}=\Xi_{t} \forall t .{ }^{10}$ Drugs' production also uses $G_{t}^{F}$ amount of guns purchased from Country A.

Also, consider a policy variable $q$, which measures an uncertain production capacity of the drug syndicate, assumed to be uniformly distributed on $(0,1]$. Intuitively, a reduction in the value of $q$ may reflect a higher degree of intensity Country B is in pursuing the 'war on drugs', be it stepping up its raiding activities of drug-production facilities or increasing the frequency of aerial spraying to destroy crop farms. The problem of the drug syndicate

\footnotetext{
${ }^{10}$ This specification basically means that the growth of the illicit human capital over time, which cannot be accumulated via deliberate acquisition of education, and is akin to a form of social/cultural capital, must necessarily reflect the overall magnitude of the illicit trade (as reflected by its accumulated flows over time). This is similar to the concept of a "standing on shoulder" effect for knowledge/ideas (Jones, 2005), where the level of illicit human capital would reflect all the learnings from/associated with all the past accumulated drug production.
} 
is then $\max _{G_{t}^{F}, L_{t}^{\xi, B}} q P_{t}^{\xi} A_{0}^{R}\left(H_{t}^{\xi, B} L_{t}^{\xi, B}\right)^{\varphi}\left(G_{t}^{F}\right)^{1-\varphi}-w_{t}^{\xi, B} H_{t}^{\xi, B} L_{t}^{\xi, B}-P_{t}^{G} G_{t}^{F}$, by choosing raw labor hours, $L_{t}^{\xi, B}$ (it has no control over the economy-wide drug-specific human capital, which is akin to a type of cultural capital), and number of guns, $G_{t}^{F}$, yielding first-order conditions of:

$$
\begin{aligned}
\varphi q P_{t}^{\xi} \xi_{t} & =w_{t}^{\xi, B} H_{t}^{\xi, B} L_{t}^{\xi, B}, \text { and } \\
q P_{t}^{\xi}(1-\varphi) \xi_{t} & =P_{t}^{G} G_{t}^{F},
\end{aligned}
$$

which, given that $H_{t}^{\xi, B}=\Xi_{t} \forall t$, equating (40) and (41), we have:

$$
\frac{\varphi}{(1-\varphi)}=\frac{w_{t}^{\xi, B} H_{t}^{\xi, B} L_{t}^{\xi, B}}{P_{t}^{G} G_{t}^{F}}
$$

Drug distribution: Even though the equilibrium price of drugs, $P_{t}^{\xi}$, reflects directly the world demand [from (9)] and supply [from (40)] of drugs, the distribution of drugs produced in Country B to households in Country A are also assumed to be costly, hence driving a wedge between the international price of drugs and ordinary tradables in equilibrium. Specifically, adopting a specification that is commonly used in models with costly distribution (Burstein et al., 2003; Agénor, 2016), distributing/smuggling a unit of drug requires using $\kappa_{t}$ units of Country B-produced ordinary tradables traded to Country $\mathrm{A}\left(C_{t}^{D i s t}=\kappa_{t} C_{t}^{A, B}\right)$. Specifically, this results in:

$$
\frac{P_{t}^{\xi}}{P_{t}^{T}}=\left(1+\kappa_{t}\right),
$$

where $\kappa_{t}=\kappa_{0}\left(\frac{\xi_{t}}{\Xi_{t}}\right)^{-\rho}$. This means the larger the quantity of current drugs production is, the lower the spread between drug price and ordinary tradable good. The larger the past accumulated drugs consumed (in other words, the more established world drugs trade is), the higher the price mark-up of drugs. ${ }^{11}$

\footnotetext{
${ }^{11}$ Alternatively, instead of such a two-step specification, the distribution cost can also be integrated into the profit maximization problem of the drug syndicate. The first-order condition obtained in that
} 
Rewriting (43), we can express the price ratio of drugs and tradables as:

$$
\frac{P_{t}^{\xi}}{P_{t}^{T}}=\left[1+\kappa_{0}\left(\frac{\xi_{t}}{\Xi_{t}}\right)^{-\rho}\right]
$$

\subsection{Market-clearing conditions}

In Country A, the equilibrium conditions of the factor markets for physical capital and labor are given by $K_{t}=K_{t}^{A}$, and $L_{t}=L_{t}^{T, A}$. For the ordinary tradable goods produced in Country A, equating supply to demand, which consists of private consumption by households in Country A, investment, government consumption, inputs used in guns-production, and those traded to Country $\mathrm{B}\left(C_{t}^{B, A}\right)$, we have

$$
Y_{t}^{T, A}=C_{t}^{A, A}+I_{t}+G_{t}^{A}+Y_{t}^{T, A G}+C_{t}^{B, A}
$$

For Country B, we first impose the symmetric equilibrium assumption, where all individuals are identical. This means, for all individuals $j \in(0,1), C_{j, t}^{B}=C_{t}^{B}, C_{j, t}^{B, B}=$ $C_{t}^{B, B}, C_{j, t}^{B, A}=C_{t}^{B, A}, L_{j, t}^{T, B}=L_{t}^{T, B}, L_{j, t}^{\xi, B}=L_{t}^{\xi, B}$. All individual and aggregate behaviors are consistent, and by implication of the identical human capital investment decisions, all individual-specific human capital equal the economy-wide average level of human capital, that is, $H_{j, t}^{\xi, B}=H_{t}^{\xi, B}, H_{j, t}^{T, B}=H_{t}^{T, B}$. On aggregate, $L_{t}^{\xi, B}+L_{t}^{T, B}=1$ holds due to symmetry.

For the ordinary tradables produced in Country B, the supply, $Y_{t}^{T, B}$, equals the demand, which consists of private consumption by households in Country B, those traded to Country $\mathrm{A}\left(C_{t}^{A, B}\right)$, and those used in distributing drugs to Country $\mathrm{A}$, $Y_{t}^{T, B}=C_{t}^{B, B}+C_{t}^{A, B}+C_{t}^{D i s t}$. Given that $C_{t}^{D i s t}=\kappa_{t} C_{t}^{A, B}$, we have

$$
Y_{t}^{T, B}=C_{t}^{B, B}+\left(1+\kappa_{t}\right) C_{t}^{A, B}
$$

There is free international trade between the two countries for the ordinary tradables.

case would have no material difference to (43). 
Therefore, the ordinary tradable goods prices are equalized across the two countries at $P_{t}^{T}$ in each period $t$. However, note that factor prices are not equalized, given the different production structures of the two countries are different.

The international market equilibrium for guns are given by

$$
Y_{t}^{G, A}=G_{t}^{G}+G_{t}^{F}
$$

\section{Equilibrium and solutions}

A dynamic international trade equilibrium for the two-country model described is a sequence of consumption and labor supply allocations for household in Country A $\left\{C_{t}^{A}, C_{t}^{A, A}, \quad C_{t}^{A, B}, L_{t}^{A}, \xi_{t}\right\}_{t=0}^{\infty}$ and individuals (in symmetry) in Country B $\left\{C_{t}^{B}, C_{t}^{B, B}, C_{t}^{B, A}, L_{t}^{T, B}, L_{t}^{\xi, B}\right\}_{t=0}^{\infty}$, physical capital stock in Country A $\left\{K_{t}^{A}\right\}_{t=0}^{\infty}$, accumulated stocks in Country B $\left\{H_{j, t}^{\xi, B}, H_{j, t}^{T, B}, \Xi_{t}\right\}_{t=0}^{\infty}$, productivity $\left\{Q_{t}^{T, A}, Q_{t}^{T, B}\right\}_{t=0}^{\infty}$, output $\left\{Y_{t}^{T, A}, Y_{t}^{T, B}, Y_{t}^{G, A}\right\}_{t=0}^{\infty}$, factor returns $\left\{w_{t}^{T, A}, r_{t}^{T, A}, w_{t}^{\xi, B}, \quad w_{t}^{T, B}\right\}_{t=0}^{\infty}, \quad$ prices $\left\{P_{t}^{T}, P_{t}^{\xi}, P_{t}^{G}\right\}_{t=0}^{\infty}$, constant government policy parameters $\left(\tau_{L}, \tau_{K}, \tau_{G}, \nu\right)$ such that, given initial stocks $K_{0}^{A}, H_{0}^{\xi, B}, H_{0}^{T, B}, \Xi_{0}>0$,

a) representative household in Country A maximizes expected utility by choosing consumption allocations for ordinary tradables, drugs, and labor supply, subject to their intertemporal budget constraint;

b) individuals in Country B maximize expected utility by choosing consumption allocations for ordinary tradables, labor supplies to both production sectors, investment in formal human capital, subject to their intertemporal budget constraint;

c) firms in the ordinary tradable goods sector in Country A maximize profits, choosing labor and private capital, taking input prices, productivity, and initial stocks as given;

$d$ ) the single guns-producing firm in Country A maximizes profits by choosing the amount of ordinary tradables to be used, taking the proprietary production technology and prices as given;

e) representative firm in Country B maximizes profits by choosing effective labor input, taking wages and productivity as given;

f) drug syndicate in Country B maximizes expected payoff by choosing effective labor input and guns, taking prices, wage, and aggregate uncertainty as given;

g) the Government in Country A maintains a balanced budget; and

h) all markets clear. 
For a given set of parameters, a stationary equilibrium is where: (i) the current-to-accumulated drug consumption ratio $\left(\Phi_{t}^{\xi \Xi}=\xi_{t} / \Xi_{t}\right)$, ordinary tradable-drugs consumption ratio of Household in Country $\mathrm{A}\left(\Phi_{t}^{C_{A} \xi}=C_{t}^{A} / \xi_{t}\right)$, ordinary tradable output-to-physical capital ratio in Country $\mathrm{A}\left(\Phi_{t}^{Y_{T A} K_{A}}=Y_{t}^{T, A} / K_{t}^{A}\right)$, Country A's tradable consumption-to-physical capital ratio $\left(\Phi_{t}^{C_{A} K_{A}}=C_{t}^{A} / K_{t}^{A}\right)$, Country A-Government's purchased guns-to-physical capital ratio $\left(\Phi_{t}^{G_{G} K_{A}}=G_{t}^{G} / K_{t}^{A}\right)$, Country A's exported guns-to-physical capital ratio $\left(\Phi_{t}^{G_{F} K_{A}}=G_{t}^{F} / K_{t}^{A}\right)$, ordinary tradable output of Country B-to-physical capital in Country A ratio $\left(\Phi_{t}^{Y_{T B} K_{A}}=Y_{t}^{T, B} / K_{t}^{A}\right)$, Country B's ordinary tradable output-to-formal human capital ratio $\left(\Phi_{t}^{Y_{T B} H_{B}}=Y_{t}^{T, B} / H_{t}^{T, B}\right)$, the two countries' relative key factor inputs' ratio $\left(\Phi_{t}^{H_{B} K_{A}}=H_{t}^{T, B} / K_{t}^{A}\right)$, Country B's household consumption-to-Country A's physical capital ratio $\left(\Phi_{t}^{C_{B} K_{A}}=C_{t}^{B} / K_{t}^{A}\right)$, and the ordinary tradable output-to-drugs produced ratio in Country $\mathrm{B}\left(\Phi_{t}^{Y_{T B} \xi}=Y_{t}^{T, B} / \xi_{t}\right)$ are all constant; (ii) factor returns, wages, and prices are constant, and (iii) the drugs-ordinary tradable market price ratio $\left(P_{t}^{\xi} / P_{t}^{T}\right)$ and the guns-ordinary tradable market price ratio $\left(P_{t}^{G} / P_{t}^{T}\right)$ are also constant.

Next, a balanced growth equilibrium (BGE) is a stationary equilibrium in which: (i) by implications of free trade, both Country A and Country B grow at a constant rate; (ii) the endogenous variables $\left(C_{t}^{A}, C_{t}^{A, A}, C_{t}^{A, B}\right.$, $\left.\xi_{t}, C_{t}^{B}, C_{t}^{B, B}, C_{t}^{B, A}, K_{t}^{A}, H_{j, t}^{\xi, B}, H_{j, t}^{T, B}, \Xi_{t}, Y_{t}^{T, A}, Y_{t}^{T, B}, Y_{t}^{G, A}\right) \quad$ all grow at a constant, endogenous rate $\gamma$; and (iii) their ratios satisfy the stationary equilibrium properties.

The dynamic system characterizing the solutions is solved for and summarized in the end of Appendix A. We study the solutions under the stationary equilibrium, characterized by the set of simultaneous equations solved for in Appendix B, with the relevant steady-state variables denoted in tildes. For simplicity, we set the ordinary tradable price to be the base price, $\tilde{P}^{T}=1$. Given the complexity of the system, stability of the economy cannot be studied analytically. However, it is established numerically by first solving for an initial BGE. Post-shocks, following a permanent change in the relevant policy parameter value(s), we then solve for a new stationary equilibrium of which the system converges to in a finite number of periods. As such, although we started off by establishing a BGE, we subsequently allow the transitory growth rates of individual variables [see, for instance, equations (80)-(84) in Appendix 
A] to diverge.

\section{Benchmark Parameterization}

For an illustrative representation of the model, we calibrate the parameters of Country A so as to match the endogenous ratios along the BGE to the first moment of the respective annual series for the United States (U.S.) in the 1990-2015 period. ${ }^{12}$ For drugs, as a self-containing measure, we focus only on the plant-based drugs of cocaine and cannabis. For Country B, to match the BGE characterization, the parameterization is based on the average value of the 5 economies of El Salvador, Guatemala, Honduras, Jamaica, and Mexico. All 5 economies: (i) are well-documented in the various publications of United Nations Office on Drugs and Crime [for instance, UNODC (2015-18)] to be major illicit cocaine or cannabis suppliers to the U.S., (ii) have formal trade sector that significantly depends on the U.S.; (iii) are controversially known for drug syndicates that involve in illicit drugs and guns trades on the American soil. On average, real GDP growth rate of the 5 economies is slightly above 2.5 percent during the 1990-2015 period, hence allowing for the setting of balanced growth rate, $\gamma=0.025$ to match that of Country A.

Given the annual time frequency and subsequent parameterization, the discount factor is at $\Lambda=0.995$, which corresponds to annual net return on physical capital of 4.5 percent. For Country A Household's utility function, the labor preference parameter, $\eta_{L}$, and the intertemporal elasticity of substitution for ordinary tradables, $\varsigma_{C A}$, are set according to Smets and Wouters (2007) at 2.0 and 0.667 (which corresponds to 1.5 in their utility specification). The inverse of Frisch elasticity of labor supply is set at a fairly standard value of 1.5, in line with meta analysis of Chetty et al. (2011). For the parameters related

\footnotetext{
${ }^{12}$ Ideally, a full Bayesian calibration is implemented. However, data series on quarterly drugs and guns' sales are not available, and the annual reporting of firearms and drugs is merely on voluntary basis and therefore have huge gaps. An illustrative moments-matching calibration strategy is therefore the only strategy we can pursue.
} 
to rational addiction of drugs, from (8), it can be seen that the price elasticity of drugs consumption is approximated in the model by $-1 / \varsigma_{\Xi}$. The elasticity of intertemporal substitution of drugs, $\varsigma_{\Xi}$, is therefore being set at $1 / 0.46=2.174$, which is within the range of estimates in Pacula et al. (2001) and in line with Grossman (2004). Given this, to satisfy the necessary condition, $\frac{\varsigma_{C A}}{\varsigma_{\Xi}}\left[\eta_{\Xi}\left(1-\varsigma_{\Xi}\right)+1\right]=0$, we set $\eta_{\Xi}=0.852$. For the rate of (anti-)persistency, $\phi$, the empirically documented estimates for cigarettes addiction by studies such as Gruber and Köszegi (2001) are within the $0.5-0.9$ range. We set $\phi=0.5$ to reflect the more addictive nature of drugs consumption. With $\tilde{\Phi}^{\xi \Xi}=\phi+\gamma$, which means the steady-state current-to-accumulated drug consumption ratio equals 0.525 .

For the overall "drug-consumption" climate factor, $\pi$, which can be interpreted as a proxy for drug liberalization, we set $\pi=0.5$ in the absence of such an existing empirical estimate. Next, using the Bureau of Economic Analysis (BEA) statistics, dividing the sum of imported consumer goods by personal consumption expenditures gives an average of 0.145 . From (11), this means $\theta=1-0.145=0.855$.

For ordinary tradable production in Country A, the elasticity value with respect to effective labor, $\beta$, is set at 0.64 , which is the common value used for United States in studies such as Christiano et al. (2005). Given the assumption $\beta=\varpi_{T}$, this means the strength of the Arrow-Romer externality with regards to physical capital stock is also 0.64. For the elasticity of labor productivity with respect to drugs consumption, we opt for a negative effect for the benchmark case by setting $v_{A}=-0.018 .{ }^{13}$ Next, based on the International Monetary Fund (IMF) capital stock dataset, the average final output-to-physical capital ratio of the United States is approximately 0.679, which is set as the value of $\tilde{\Phi}^{Y_{T A} K_{A}}$ along the balanced growth path. Likewise, applying the household consumption share as a percentage of GDP series from the BEA to the IMF capital stock dataset, we calculate Country A's tradable consumption-to-physical capital ratio in the

\footnotetext{
${ }^{13}$ The value corresponds to North America's annual prevalence rate of drugs consumption (UNODC, 2018). This means the parameterization strategy involves implicitly assuming that the prevalence of drug usage in the population translates to an equivalent effect on the aggregate labor productivity.
} 
BGE, $\tilde{\Phi}^{C_{A} K_{A}}=0.453$. From (14), using also the employment and wage data from the $\mathrm{BEA}, A_{t}^{T, A}=\frac{\beta\left(Y_{t}^{T, A} / L_{t}^{T, A}\right)}{w_{t}^{T, A}}=14.76$ is calculated. From $(17)$, this means $A_{0}^{A}=14.59$. After that, using (18), given all the other parameterization, the productivity parameter, $Q_{0}^{T, A}=0.1213$ is estimated. Given these calibrations, and using the first-order conditions for $\tilde{r}^{T, A}$, we determine the physical capital depreciation rate, $\delta^{K}$, at a relatively high 0.2 , so as to give an annual net (of depreciation) return on physical capital of 4.5 percent.

For guns, we rely on the various editions of the annual statistical update on firearms production and sales published by the Bureau of Alcohol, Tobacco, Firearms and Explosives, United States (ATF) for the parameterization. In the period of 1990-2015, 6.2 percent of total guns manufactured in the United States are exported, which gives us the ratio of $\tilde{G}^{F}$ over $\tilde{Y}^{G, A}$, and indirectly, its share against those purchased by the government in Country A, $\tilde{G}^{G}$. For the tax rate on guns production, $\tau_{G}$, based on the total tax revenues collected under the National Firearms Act (occupational tax plus transfer \& making tax) and the estimated revenue of the guns and ammunition industry [see Brauer (2013) and various reported figures by the Firearms Industry Trade Association (NSSF)], $\tau_{G}=0.003$ is estimated. For the production parameters, in the absence of existing estimates, the time-invariant shift parameter, $A_{0}^{G}$, is set at one. Further, a very small elasticity of guns' production with respect to tradable inputs is set at $\chi=0.05$, which given the assumption $\omega=1-\chi=0.95$, means guns production benefits immensely from knowledge spillover associated with the economy wide physical capital stock - a reasonable feature consistent with anecdotal evidence.

For the Government in Country A, the labor and physical capital income tax rates are calibrated based on the average wage income tax rate faced by a childless single person at $100 \%$ of average earnings (as estimated by the OECD) and the statutory corporate income tax rate, yielding $\tau_{L}=0.174$ and $\tau_{K}=0.350$ respectively. The share of government consumption as a percentage of the domestically produced tradables is estimated using the BEA statistics again, which gives $\nu=0.340$. Lastly, the fraction of realizable value 
from confiscated drugs, $z$, is set at a very low rate of 0.05 .

For the preference parameters in Country B, for consistency and due to a general lack of country-specific macroeconomic studies for the sample economies, the same values for the intertemporal elasticity of substitution, the inverse value of Frisch elasticity, and the labor preference parameter are used, where $\varsigma_{C B}=0.667, \psi_{B}=1.5$, and $\eta_{B}=2.0$. The share of domestically produced ordinary tradables for households in Country B is set at $\varrho=0.8$, which is in line with the averages of the sample economies. For the remaining parameters, following Mocan et al. (2005), the formal/legal human capital depreciation rate is set at 0.05 , while the parameter for the efficiency of formal/legal human capital investment, $\Theta_{H B}$, is set at 0.156. Together, these yield steady-state human capital investment $\left(\delta^{H B} / \Theta_{H B}\right)$ that approximates the average expenditure per student in tertiary education (32 percent of GDP per capita) for the five sample economies. Given that our stylized model does not separately model drugs farming, processing, and trafficking in distinct details, the choice of this combination of parameters allow us to determine an initial steady-state share of labor hours allocated to drugs production at 0.15 , which is consistent with the usual estimates of employment/time spent in coca farming by the Andean farmers [see Angrist and Kugler (2008), Organization of American States (2013), and the various annual reports of UNODC].

For ordinary tradable production in Country $\mathrm{B}$, the production elasticity, $\alpha$, is set at 0.6, which is in line with the average estimated labor share of Guerriero (2012) for the 5 economies. Given that $\phi_{1}=1-\alpha$ must hold to generate endogenous growth in Country B, the learning externality is set at 0.4, consistent with studies such as Agénor (2016). For the shift parameter, $Q_{0}^{B}=9.41$, its value is derived residually from the relative human capital (or relative wage) ratio along the BGE, where $\tilde{H}^{T, B} / \tilde{H}^{\xi, B}=\tilde{w}^{\xi, B} / \tilde{w}^{\xi, B}=$ $[\varphi q \vartheta(1+\tilde{\kappa})(\phi+\gamma)] /\left[(1-\vartheta) \alpha Q_{0}^{B} Q_{0}^{T, A}\left(A_{0}^{A}\right)^{\beta}(\phi+\gamma)^{v_{A} \beta} \vartheta^{\alpha}\right]$, the value of which in turn depends on the parameterization for the drugs sector. 
For the drugs sector, the initial value of the relative human capital ratio, $\tilde{H}^{T, B} / \tilde{H}^{\xi, B}$, is set at 0.25 to reflect a relatively low formal human capital in relation to drug-specific human capital. This, given an initial $\tilde{w}^{\xi, B}=1$, yields $\tilde{w}^{T, B}=4$. With $\tilde{P}^{T}=1$, the steady-state drug price, $\tilde{P}^{\xi}$, is parameterized based on the average wholesale price of cocaine base (USD'000 per kg) in 3 of the sample economies with data (Jamaica: USD 5.795, Guatemala: USD 9.329, Honduras: USD7.3), yielding $\tilde{P}^{\xi}=7.5$. This then gives $\tilde{\kappa}=6.5$. In the absence of reliable statistics, and given that it is a policy arrangement that will be evaluated extensively in our policy experiments, we set the initial value affecting drugs production capacity, $q=0.5$. Given the values of $\tilde{w}^{\xi, B}, \tilde{\Phi}^{\xi \Xi}, q$, and $\tilde{L}^{\xi, B}$, using (40), we can estimate the elasticity of drugs production with respect to drug-specific effective labor, $\varphi$, to be 0.076 . Lastly, given a value of $\rho=0.05$, the shift parameter for distribution cost, $\kappa_{0}$, equals 6.294 .

The remaining variables are calibrated as follows. With all the parameters determined, we can calculate the steady-state value of ordinary tradable consumption in Country B and A using expressions derived in Appendix B, yielding $\tilde{C}^{B}=0.516$ and $\tilde{C}^{A}=1.296$. Given that $\tilde{\Phi}^{C_{A} K_{A}}=0.453$, we can then determine the benchmark value for $\tilde{K}^{A}{ }^{14}$ For the steady-state price of guns, $\tilde{P}^{G}$, we first estimate a price ratio of $\tilde{P}^{\xi} / \tilde{P}^{G}$. While precise sales estimates for both drugs and guns are impossible to pin down, we can derive a price ratio based on the respective quantity of production, as well as the estimated total industry values (NSSF and ATF for guns, UNOCD for drugs). We estimated $\tilde{P}^{\xi} / \tilde{P}^{G}=1.82$, which gives $\tilde{P}^{G}=4.12$. From (41), we also calculate $\tilde{P}^{G} \tilde{G}^{F}=1.878$, which then gives $\tilde{G}^{F}=0.456$. Country A's exported guns-to-physical capital ratio along the BGE is then estimated to be $\tilde{\Phi}^{G_{F} K_{A}}=0.159$. To ensure the

${ }^{14}$ As shown in Appendix B, in order for the existence of non-cornered solution for $\tilde{C}^{B}>0$, the parameterization must satisfy the analytical conditions, $\Lambda^{-1}(1+\gamma)^{\varsigma_{C B}^{-1}}-\left(1-\delta^{H B}\right)>0$, which is indeed the case for our benchmark. In addition, it is also common practice, when implementing numerical policy experiments for transition dynamic analysis in the later section, to normalize the initial values of $\tilde{K}^{A}$, $\tilde{C}^{B}$, and $\tilde{C}^{A}$ from the unadjusted value to an index of one. These have no effect on the computations of the gross growth rates of the aforementioned variables. 
parameterization is realistic, we subsequently normalized the guns-to-consumption ratio in Country A of 0.35 , a value that approximates the proportion of American households with firearms (Smith and Son 2015). From Appendix B, $\tilde{\Phi}^{C_{A} K_{A}}=\left\{A_{0}^{R} \pi^{-\varsigma_{C A}}(\phi+\gamma)^{\frac{\varsigma_{C A}}{\varsigma_{\Xi}}-\varphi}(1-\vartheta)^{\varphi}(1+\tilde{\kappa})^{\varsigma_{C A}-\varphi}\left(\tilde{P}^{G}\right)^{\varphi}[q(1-\varphi)]^{-\varphi}\right\} \tilde{\Phi}^{G_{F} K_{A}}$ which then allows us to derive the last parameter value, $A_{0}^{R}=1.291$. In sum, all the parameter values are summarized in Table 1 and 2.

\section{$5 \quad$ Illustrative Policy Experiments}

In the policy debate on modern drug control, a key controversy often surrounds the question of whether it is most effective for intervention to be in the final consumer stage (also, prohibition vs. legalization), the initial production stage (interdiction policy at source country), or the intermediate trafficking/transshipment stage. In addition, there are also concerns about the impact of the illicit gun trade on drugs trades (and related conflicts). Given the rigorous (albeit stylized) analytical foundations of our model, we set out to answer some of these questions by implementing numerical policy experiments using the parameterized model. We consider four individual policies: (i) a relaxation in the overall climate for drug consumption in Country A (increase in $\pi$, as a proxy for relaxed legislation); (ii) a decrease in the drug production capacity in Country B (decrease in $q$, as a proxy for more prohibitive supply-side policy); (iii) an increase in the shift parameter for drug distribution, $\kappa_{0}$, so as to reflect costlier drug transshipment; and (iv) an increase in the tax rate for guns production, $\tau_{G} \cdot{ }^{15}$ For consistency of comparison, all simulated policy experiments involve a permanent one percent change from the respective initial parameter

\footnotetext{
${ }^{15}$ It is worth pointing out that, to save space, a policy experiment with regards to human capital investment efficiency in Country B, $\Theta_{H B}$, is not presented. As would be seen, all 4 drug-control related polices considered have only level and not growth effect on Country B's ordinary tradable production in the steady state. A permanent increase in $\Theta_{H B}$ is the obvious policy to raise the growth rate of tradables in Country B (for instance, doubling $\Theta_{H B}$ will raise steady-state growth rate of $Y^{T, B}$ by 1.1 percent). However, the policy largely has no steady-state effect on the growth rates of key variables in Country A, as well as the drugs and guns trades, therefore not being explicitly discussed.
} 
values. Although these policy experiments involve changes in what some would argue as deep parameters, the main objective here is to understand the relative impacts and model behaviors associated with the intervention at vastly different stages of such a "unified" world (which remains a huge knowledge gap in the present literature, as this cannot be supported by partial equilibrium frameworks). The experiments implemented would therefore be enough to meet the objectives without adding further complications.

\subsection{Is legalization or prohibition the better approach?}

To examine this question, suppose there is a permanent one-percent increase in the value, $\pi$. This can be interpreted as a growing relaxation of drug control policy at the final consumer market, hence a proxy for potential legalization of drug possession. The steady-state effects are summarized in Table 3. In the benchmark case, the current-period drug consumption/production $(\tilde{\xi})$ increases by 0.2 percent from the initial steady state. For Country A, this corresponds to a 0.2 percent increase in private consumption, given the constancy of private household consumption allocation between ordinary tradables and drugs in Country A in the long run $\left(\tilde{\Phi}^{C_{A} \xi}\right)$. However, the additional drug consumption leads to a negative effect onto labor productivity, which over the long run, translates to a lower growth path for both physical capital stock and tradable output in Country A (declining by 0.8 percent). This divergence of growth path between consumption and production in Country A is mainly due to two reasons: (i) a reallocation of resources in Country A, from formal investment and tradable production activities to those of consumption (for both tradables and drugs), as can be seen in (45). As such, although the economy converges to a new stationary equilibrium post-shock, the level of consumption and capital stock has changed, resulting in the tradable consumption-to-physical capital ratio $\left(\Phi_{t}^{C_{A} K_{A}}=C_{t}^{A} / K_{t}^{A}\right)$ being higher in the new equilibrium; and (ii) although the growth rate of tradable output in Country B is largely unaffected in the long run (as its 
level of production is directly dependent on the production level in Country A), the actual production level of ordinary tradable production in Country B declines (due to tradable production level in Country A having declined). This leads to lower levels of household income and consumption in Country B, hence translating to a lower import demand of tradable goods from Country A. In combination, these contribute to a lower transitory growth rate of investment and hence tradable production in Country A.

At the same time, drug production in Country B benefits from the "standing on shoulder" learning effect associated with the overall expansion in illicit drug trades, which translates to an expansion in the drug-specific human capital stock. Although the optimality condition for labor supply in Country $\mathrm{B}\left(\tilde{H}^{T, B} \tilde{w}^{T, B}=\tilde{H}^{\xi, B} \tilde{w}^{\xi, B}\right)$ means the investment in formal human capital will rise too, this further reallocates individuals' spending away from consumption of ordinary tradables. This decline in domestic consumption demand, as well as the scale-effect associated with the decline in the production level in Country A, contributes to a decline in the level of formal tradable production in Country B, despite the policy being growth-neutral in the long-run. Lastly, the decline in the growth rate of both $\tilde{Y}^{T, A}$ and $\tilde{K}^{A}$ leads to a decline in the growth rate of guns production, given that its production uses the former as input and benefits from the spillover effect of the latter. Although not explicitly presented, it is worth noting that the simulation results with respect to a change in $\pi$ are largely monotonic, in that, an opposite experiment of a tougher drug legislation (decline in $\pi$ ) delivers the opposite effects (albeit at slightly different magnitude) for all the key variables. In addition, as seen in the sensitivity results presented, the policy effects are mostly robust to key parameter changes, including both positive and negative elasticities with regards to labor productivity in Country A. In other words, irrespective of whether drug consumption improves or reduces labor productivity in Country A, the policy effects associated with a change in $\pi$ are robust, and the production-consumption growth trade-off in Country A is consistently observed. 
"Is legalization or prohibition the better approach?" Based on the analysis, stricter drug control policy appears to be growth-enhancing to formal tradable activities (including physical capital investment) in the long run, though households in Country A experience a decline in consumption growth. As such, if the maximization of private consumption growth (often a welfare indicator) is the leading objective over production growth-maximization, then there is a rationale for Country A to relax its drug-control rule at the cost of some deceleration in the growth of its tradable activities.

\subsection{Does more interdiction \& prohibitive supply-side policy work?}

Next, we consider policy targeting directly the supply-side, which includes measures that attempt to eradicate drug cultivation. Such policies can be proxied by a permanent decrease in the value of the policy variable $q$, which affects the outcome of drug production in Country B. We simulate a one-percent decrease in $q$ from the initial value, with results on the steady-state effects presented in Table 3 . This has a negative effect on the level of drug production, hence translating to a decline in the current-to-accumulated drug consumption ratio $\left(\Phi_{t}^{\xi \Xi}\right)$ from 0.525 in the initial steady state to 0.523 in the new stationary equilibrium. This translates to a decline in the stock of drug-specific human capital, which for a given relative wage ratio, means an increase in the level of formal/legal human capital stock in Country B. This in turn leads to a higher level of ordinary tradable production in Country B. This expansion in the production level of formal sector in Country B translates to an increase in the growth of domestic consumption (in Country B) and, given the trade-dependency between both countries, a higher level of trades between the two countries, and hence a long-run increase in tradable production in Country A by 1.6 percent. At a given tradable output-to-physical capital ratio, this means the transitory growth rate of 
physical capital stock also rises by 1.6 percent. By implication, the growth rate of private consumption in Country A also increases, but at a lower rate of 0.3 percent due to the overall tradable consumption-to-physical capital ratio $\left(\Phi_{t}^{C_{A} K_{A}}\right)$ having declined from 0.453 in the initial steady state to 0.445 in the new stationary equilibrium (in other words, although the aggregate resources in Country A has expanded, more of the additional resources are allocated to investment than consumption).

Nevertheless, the expansion in overall consumption has an unintended income effect: it also leads to an increase in demand for drugs. In the long run, despite the initial drop in the level of drug production, the growth rate of current-period drug production will eventually increase to trace the growth rate of private consumption growth in Country A. In other words, the expansion in demand over the long run for drugs will eventually overcome the initial contractionary level effect from the supply side, hence leading to a slight growth in price of drugs (+0.1 percent) in the new equilibrium.

In terms of the sensitivity analysis results, the long-run policy effects appear to be robust across most parameters. However, when the demand of tradable inputs in guns production is a lot more elastic $(\chi=0.5)$, the steady-state expansionary growth effects observed for tradable production and physical capital in Country A are reversed. In this instance, the contractionary effect in guns production (associated with the decline in drug supplies) weights more heavily on tradable production in Country A, and this negativity dominates the international trade-expansionary effect associated with the higher levels of tradable production in both countries. In sum, our results show that more prohibitive supply-side intervention appears to be effective in promoting growth in production and trades in the formal sectors of both countries. However, if the goal is to reduce the size of the global illicit drug trades, then a demand side intervention appears to be more effective. Indeed, this is consistent with the real-world phenomenon observed: despite many 'war on drug' efforts undertaken by certain Latin American governments over the decades, the drug trades have persisted, with only the 'balloon effect' observed - drug syndicates 
merely transformed and re-emerged in another location or in different means/mode of operations over time.

\subsection{An increase in drug distribution cost}

It is often perceived that growing interdiction of transshipments in the recent decades had successfully elevated drug prices to a very high level at the final wholesale and retail levels, which in turn significantly reduced global drug consumption. Is this a universally good policy? We address this question by simulating a permanent one-percent increase in the distribution cost parameter, $\kappa_{0}$. The steady-state effects are summarized in Table 4. Predictably, the steady-state drug price increases by 6.5 percent. For a given tradable price, this means drug is relatively more expensive than tradable good, hence leading to an initial reallocation towards tradable consumption by the private individuals. At the same time, by virtue of (46), the higher distribution cost means more ordinary tradables produced in Country B are being used in distributing drugs to Country A, therefore resulting in a drop in the level of private consumption in Country B.

In the long run, the growth effect turns out to be bad than good, as the adverse effects associated with the decline in consumption demand and overall income in Country B outweigh those associated with the expansion in tradable demand in Country A, thereby resulting in a net negative international trade-expansion effect. This is

despite the fact that the decline in accumulated stock of drug-specific human capital means, at a given relative wage ratio, the level of formal human capital stock increases, leading to a permanent increase in the growth rate of relative human capital stock and therefore, an expansion in the level of ordinary tradable production in Country B. However, as the growth of formal human capital is almost negligible, the positive effect on tradable production growth in Country B is therefore only temporary and muted in the long run. The decline in drugs production also leads to a steady-state drop in the 
demand of the input of guns, the production of which uses ordinary tradables in Country A. Indeed, the negative trade effect dominates (tradable consumption growth in Country A) to the extent that, the transitory growth rate of ordinary tradable production in Country A declines by 1.8 percent in the new stationary equilibrium. Physical capital stock declines by the same magnitude, and the declining tradable production growth in Country A reinforces the decline of private consumption in Country B. Finally, in terms of illicit drug trade, production supply, aided by a persistent demand, eventually catches up to neutralize the additional transshipment cost, hence resulting in the current-period

drug production growing at the same rate as private consumption in Country A, at 0.11 percent. In sum, these results show that, drug-control intervention at the transshipment stage appears to not be an effective policy compared to the previous two experiments considered. The sensitivity analysis results largely reaffirm these findings.

\subsection{The controversial drug-gun trade nexus}

A permanent one-percent increase in the tax rate on guns production, $\tau_{G}$ is simulated. The steady-state effects of selected variables are presented in Table 4. Recall that our stylized model essentially treats all illicit component of world gun trades as the exported share, whereas the purchase made by the government in Country A can be interpreted as all other legal purchases. As such, although this experiment does not shed light on the heated domestic gun-control debate that has been taking place in the United States recently, it does refer to a taxation/fee that is levied on the production of all guns. In Table 4, it is seen that the tax rate is growth-neutral on drugs production in the long run, despite guns being modelled as a factor of production for drugs. Given this, the long-run effect on current-to-accumulated drug consumption ratio is also muted, therefore leading to growth neutrality in the relative human capital stock in Country B too. At a given ordinary tradable-drugs consumption ratio, the long-run growth neutrality of $\tilde{\xi}$ means 
the growth effect of private consumption of tradables in Country A is also muted. To rationalize this, the higher tax levied at production is likely to lead to an instantaneous decline in guns' supply. At the initial factor-price ratio for guns production, this negative supply shock leads to a decrease in drugs production on impact and by implication, the growth rate of drug-specific human capital. At a given initial level of relative stock of human capital, this translates to an increase in the growth rate of relative human capital stock in Country B in the short run. However, the decline in current-period drug production means drug price also increases, leading to a decline in drug consumption. At an initial optimal consumption allocation, household in Country A consumes less, leading to a decline in ordinary tradable production in Country B. Nevertheless, given that the optimality condition for drugs production remains unchanged, the actual world price of guns remains unchanged. From the optimality condition in (23), the guns manufacturer eventually makes up for this production levy by producing more guns $(+0.01$ percent $)$ and in the process, demands more tradable inputs. This translates to a steady-state increase of the same magnitude for the growth of tradable production and physical capital stock in Country B, and consequently via international trade, the growth of private consumption in Country B. As all the other production dynamics in Country B are unaffected by this policy in the long-run, growth neutrality is eventually observed for the growth rates of tradables, relative human capital stock, and drugs production in Country B as the economy converges to the new steady state.

The experiment shows that, any non-quota gun-control policy, such as a tax levied on production, will have no long-term implication on illicit guns trade, if there is no fundamental change to its demand and supply. This, together with the limited long-run growth effect observed with transshipment intervention, is consistent with the logic of the "drug-producer compensates with increased higher productivity" effect documented in Ortiz (2003, 2009), hence partly explains the limited effect of drug trafficking-control measures in the region (Reuter and Trautmann, 2009). 


\subsection{Further analysis - Drug policies and trade openness}

Based on the results of the individual policies considered, the long-run growth effects of the two major drug control policies are further evaluated in the context of varying trade openness in Table 5 and 6 . Specifically, in Table 5, the first policy experiment with regards to $\pi$ is repeatedly simulated with different parameterization of the share of domestically produced tradables in the aggregate consumption of household in Country A, $\theta$. In addition, given the well-documented significance of the (anti-) persistency rate, $\phi$, in the rational addiction literature, we also evaluate the policy outcome across $\phi \in$ $(0.1,0.9)$. The initial value of $\phi$ is structurally significant in that, for any given value of $\theta$, there is a range of value for $\phi$ where the growth effect of production in Country $\mathrm{A}$ is positive, when drug law is liberalized. Indeed, the more open Country $\mathrm{A}$ is ( $\operatorname{smaller} \theta$ ), the wider the range of $\phi$ with positive growth effect, hence providing greater possibility for drug liberalization policy to be growth-enhancing. Overall, despite a completely different framework, our findings are mainly consistent with Becker et al. (2006), in that, the more addictive drug is, the greater the increase in the social cost from using greater enforcement; the less past addiction influences current consumption, there is greater room for potential benefits in pursuing drug liberalization.

In Table 6, we assess the policy that is more relevant to Country B, which is the experiment of a permanent decrease in the value affecting drugs production, $q$, across a range of Country B' consumption share of domestically produced tradables $(\varrho)$. Moreover, given that the guns' production elasticity, $\chi$, is observed to be a critical parameter in the benchmark analysis, we also evaluate the policy effectiveness (in terms of private consumption growth in Country B) across different $\chi$ values. A clear structural break-point for $\chi$ is observed for the different $\varrho$ values considered, below which the growth effect on consumption in Country B is positive. It appears that, the more "closed" Country B is (in terms of its individuals' consumption share), the lower 
the structural break-point for $\chi$ is. Given that the Arrow-Romer externality effect in guns production sector is given by $\omega=1-\chi$, this provides a natural policy interpretation. In essence, if Country B is more "closed" (higher $\varrho$ value), in order for prohibitive supply-side policy to be growth-enhancing to household consumption in Country B, the learning externality or degree of knowledge spillover in the guns-production industry would need to be higher. In other words, this means the knowledge/learning effect brought about from the firearms trade to Country B will have to be a lot larger if the economy is characterized a lack of trade openness.

\section{Concluding Remarks}

The illicit drug trade, as well as its associated illicit trades in firearms, remains highly persistent despite the plethora of control policies proposed globally. In this context, the activities by drug-related syndicates based in the Central American and Caribbean regions continue to be a subject of frequent press coverage in the United States. In this paper we present a unified growth framework that includes the integration of formal international trade and illicit drug-for-gun trade, as well as different drugs control policies aimed at consumers, producers and intermediate trans-shipments. Specially, we contributes to the literature by developing a two-country, multi-sectorial dynamic general equilibrium model of endogenous growth with drugs and guns trade.

This approach allowed us to fill the three major gaps in existing analytical literature, namely: (i) examine the dynamic tradeoff and growth implications of drug-control policies across the full spectrum of the illicit drug trades in both consuming and producing countries; (ii) explicitly model the firearm market-albeit in a stylized manner - and explore its link to the illicit drugs trade; (iii) analyze the spillover effects between illicit trades and formal international trades.

The numerical policy experiments (using parameterized version of the model) 
uncover a production-consumption growth trade-off that is not previously documented in the literature. We show that if maximizing household consumption growth is the policy priority in drug-consuming countries, then drug liberalization could be growth enhancing. In fact, our results show that in the absence of a fundamental change to drug demand, drug control policies are unlikely to reduce illicit trades for drugs and guns in the long run. This is consistent with the argument that managing potential addiction by treating it as a public health issue as opposed to a criminal issue is the optimal policy choice. On the contrary, direct supply-side policy aimed at eradicating drug cultivation (the normal "War on Drugs" approach) in supplying countries would only be effective if there is a high degree of trade openness in these countries.

Despite the contributions, there remain shortcomings that future studies can address. While we believe the model provides a better 'world-view' to the illicit trades, some features of vertically-integrated models, such as those highlighted in Mejía and Restrepo (2016) were not included in our analysis for brevity. Our model therefore is unable to account for phenomenon such as the 'balloon effect' (the ability of drug production to move to a new location or across international borders), and any resulting spike in violence and conflicts associated with drugs trades.

In addition, while we accounted for rational addiction in the modelling of drug-consumers, we omitted the possibility of asymmetric information and costly search, such as in Galenianos et al. (2012). The same can be said for the illicit guns trade, which we modelled in a very simplistic manner. For future research, any attempt to "expand the universe" of the model will necessarily involve accounting for these features.

Furthermore, with greater availability of data, given the notorious volatility in drug supply and prices, the introduction of more stochastic elements into a dynamic model to capture more realistic short-term movements in drug prices is also warranted. 


\section{References}

Agénor, P., 2016. Optimal fiscal management of commodity price shocks. J. Dev. Econ. 122 (C), 183-196.

Alexeev, M., Janeba, E., Osborne, S., 2004. Taxation and evasion in the presence of extortion by organized crime. J. Comp. Econ. 32 (3), 375-387.

Angrist, J., Kugler, A., 2008. Rural windfall or a new resource curse? Coca, income, and civil conflict in Colombia. Rev. Econ. Stat. 90 (2), 191-215.

Bagley, B.M., 2012. Drug trafficking and organized crime in the Americas: Major trends in the twenty-first century. Woodrow Wilson Center Update on the Americas. Woodrow Wilson Center.

Bagley, B.M., Rosen, J., 2015. Drug Trafficking, Organized Crime, And Violence in the Americas Today. University Press of Florida.

Becker, G.S., Murphy, K., 1988. A theory of rational addiction. J. Polit. Econ. 96 (4), 675-700.

Becker, G.S., Grossman, M., Murphy, K., 2006. The market for illegal goods: The case of drugs. J. Polit. Econ. 114 (1), 38-60.

Blackburn, K., Neanidis, K., Paola Rana, M., 2017. A theory of organized crime, corruption and economic growth. Econ. Theory Bull. 5 (2), 227-245.

Blumstein, A., 1995. Youth violence, guns, and the illicit-drug industry. J. Crim. Law Criminology 86 (1), 10-36.

Blumstein, A., Rivara, F., Rosenfeld, R., 2000. The rise and decline of homicide - and why. Annu. Rev. Pub. Health 21, 505-541.

Brauer, J., 2013. The US firearms industry: Production and supply. Working Paper 14. Small Arms Survey, Geneva, Switzerland.

Bureau of Alcohol, Tobacco, Firearms and Explosives, United States (ATF-US) (2017). Firearms commerce in the United States: Annual statistical update 2017. U.S. Department of Justice.

Burstein, A., Neves, J.C., Rebelo, S., 2003. Distribution costs and real exchange rate dynamics during exchange-rate-based stabilizations. J. Monet. Econ. 50 (6), 1189-1214.

Buxton, J., 2015. Drug Crop Production, Poverty, and Development. Open Society Foundation, New York.

Caulkins, J., Feichtinger, G., Tragler, G., 2001. Optimal dynamic allocation of treatment and enforcement in illicit drug control. Oper. Res. 49 (3), 352-362.

Caulkins, J., Kleiman, M., 2018. Lessons to be drawn from U.S. drug control policies. Eur. J. Criminal Policy Res. 24, 125-144.

Chetty, R., Guren, A., Manoli, D., Weber, A., 2011. Are micro and macro labor supply elasticities consistent? A review of evidence on the intensive and extensive margins. Am. Econ. Rev. 101 (3), 471-475.

Christiano, L., Eichenbaum, M., Evans, C., 2005. Nominal rigidities and the dynamic effects of a shock to monetary policy. J. Polit. Econ. 113 (1), 1-45.

Chumacero, R.A., 2010. Evo, Pablo, Tony, Diego, and Sonny: general equilibrium analysis of the market for illegal drugs. In: Keefer, P., Loayza, N. (Eds.), Innocent Bystanders: Developing Countries and the War on Drugs. The World Bank, 165-194. 
Costa Storti, C., De Grauwe, P., 2009. The cocaine and heroin markets in the era of globalisation and drug reduction policies. Int. J. Drug Policy 20, 488-496.

Demombynes, G., 2011. Drug trafficking and violence in Central America and beyond. Background Case Study for World Development Report 2011. World Bank.

Dills, A., Miron, J., Summers, G., 2010. What do economists know about crime? In: NBER Chapters: The Economics of Crime: Lessons for and from Latin America. NBER, Inc., 269-302.

Galenianos, M., Pacula, R.L., Persico, N., 2012. A search-theoretic model for the retail market for illicit drugs. Rev. Econ. Stud. 79 (3), 1239-1269.

Greenfield, V., Bond, C., Crane, K., 2017. A household model of opium-poppy cultivation in Afghanistan. J. Policy Modell. 39 (5), 741-761.

Grossman, H., Mejía, D., 2008. The war against drug producers. Econ. Governance 9 (1), $5-23$.

Grossman, M., 2004. Individual behaviors and substance use: the role of price. NBER Working Paper 10948, Cambridge, MA: NBER.

Gruber, J., Köszegi, B., 2001. Is addiction rational? Theory and evidence. Q. J. Econ. 116 (4), 1261-1303.

Guerriero, M., 2012. The labour share of income around the world: Evidence from a panel dataset. Dev. Econ. \& Public Policy Working Paper 32, University of Manchester.

Jones, C., 2005. Growth and Ideas. In: Aghion, P., Durlauf, S. (ed.) Handb. Econ. Growth, 1063-1111.

Kilmer, B., Sohler E., Caulkins, J., Midgette, G., Pacula, R., Reuter, P., Burns, R., Han, B., Lundberg, R., 2014. What America's users spend on illegal drugs: 2000-2010. RAND Corporation.

Kugler, M., Verdier, T., Zenou, Y., 2005. Organized crime, corruption and punishment. J. Pub. Econ. 89 (9-10), 1639-1663.

Kuziemko, I., Levitt, S., 2004. An empirical analysis of imprisoning drug offenders. J. Pub. Econ. 88, 2043-2066.

Langton, J., 2011. Gangland: The Rise of the Mexican Drug Cartels from El Paso to Vancouver. John Wiley \& Sons.

Latin American Commission on Drugs and Democracy, 2016. Drugs \& Democracy: Toward a paradigm shift. Global Commission on Drug Policy.

Levitt, S.D., Venkatesh, S., 2000. An economic analysis of a drug-selling gang's finances. Q. J. Econ. 115 (3), 755-789.

London School of Economics (LSE), 2014. Ending the Drug Wars. Report of the LSE Expert Group on the Economics of Drug Policy, May, LSE.

Mejía, D., Posada, C.E., 2008. Cocaine production and trafficking: What do we know? Policy Research Working Paper 4618. World Bank.

Mejía, D., Restrepo, P., 2008. The war on illegal drug production and trafficking: An economic evaluation of Plan Colombia. Documento CEDE 19. Universidad de los Andes, CEDE.

Mejía, D., Restrepo, P., 2016. The economics of the war on illegal drug production and trafficking. J. Econ. Behav. \& Org. 126, 255-275. 
Millán-Quijano, J., 2019. Internal cocaine trafficking and armed violence in Colombia. Econ. Inquiry 58 (2), 624-641.

Miron, J.A., 2001. Violence, guns, and drugs: A cross-country analysis. J. Law Econ. 2 (2), 615-634.

Mocan, H.N., Billups, S., Overland, J., 2005. A dynamic model of differential human capital and criminal activity. Economica 72 (288), 655-681.

Naranjo, A., 2007. Insurgents, Drug Lords and Anti-Drug Supply Policies in the Andes (Ph.D. dissertation). Department of Economics, Stockholm University.

Organization of American States (OAS), 2013. The economics of drug trafficking, Chapter 4 in: The Drug Problem in the Americas. Washington DC.

Orphanides, A., Zervos, D., 1995. Rational addiction with learning and regret. J. Polit. Econ. 103, 739-758.

Ortiz, C.H., 2003. La guerra contra las drogas es contraproducente: un análisis económico de equilibrio general. Lecturas de Economía 58, 47-68.

Ortiz, C.H., 2009. The war on drugs is counterproductive, once again. Lecturas de Economía $71,19-42$.

Pacula, R., Grossman, M., Chaloupka, F., O’Malley, P., Johnston, L., Farrelly, M., 2001. Marijuana and youth. In: Gruber, J. (eds.), Risky behavior among youths: An economic analysis. University of Chicago Press, 93-191.

Pacula, R., Kilmer, B., Grossman, M., Chaloupka, F., 2010. Risks and prices: The role of user sanctions in marijuana markets. B.E. J. Econ. Analysis Policy 10 (1), Art. 11.

Reuter, P., 2008. Can production and trafficking of illicit drugs be reduced or merely shifted? Policy Research Working Paper 4564. World Bank.

Reuter, P., 2010. Understanding the Demand for Illegal Drugs. National Academy Press. Washington, DC.

Reuter, P., Trautmann, F., 2009. A Report on Global Illicit Drug Markets 1998-2007. European Communities.

Rhodes, W., Johnston, P., Han, S., McMullen, Q., Hozik, L., 2002. Illicit drugs: Price elasticity of demand and supply. Abt Associates, Cambridge, MA.

Rydell, P., Caulkins, J., Everingham, S., 1996. Enforcement or treatment? Modeling the relative efficacy of alternatives for controlling cocaine. Oper. Res. 44 (5), 687-695.

Smets, F., Wouters, R., 2007. Shocks and frictions in US business cycles: A Bayesian DSGE approach. Am. Econ. Rev. 97 (3), 586-606.

Smith, T.W., Son, J., 2015. General Social Survey: Trends in Gun Ownership in the United States, 1972-2014. NORC at the University of Chicago.

United Nations Office on Drugs and Crime (UNODC), 2014. World Drug Report 2014. United Nations publication.

UNODC, 2015-18. World Drug Reports. United Nations publication.

Whitford, A.B., Yates, J., 2009. Presidential Rhetoric and the Public Agenda: Constructing the War on Drugs. Johns Hopkins University Press. 
Table 1

Benchmark Parameter Values, Country A

\begin{tabular}{|c|c|c|}
\hline Parameter & Description & Value \\
\hline \multicolumn{3}{|c|}{ Country A - Households } \\
\hline$\Lambda$ & Subjective discount factor & 0.995 \\
\hline$\eta_{L}$ & Preference parameter, disutility of labor & 2.0 \\
\hline$\psi$ & Inverse of Frisch elasticity of labor supply & 1.5 \\
\hline$\varsigma_{C A}$ & Elasticity of intertemporal substitution, ordinary goods & 0.667 \\
\hline$\pi$ & Overall climate factor, drugs possession & 0.5 \\
\hline$\eta_{\Xi}$ & Preference parameter, rational addiction & 0.852 \\
\hline$\phi$ & Rate of (anti-)persistence, accumulated drugs consumed & 0.5 \\
\hline$\theta$ & Share of domestically produced ordinary tradables & 0.855 \\
\hline$\varsigma_{\Xi}$ & Elasticity of intertemporal substitution, drugs & 2.174 \\
\hline$\delta^{\bar{K}}$ & Physical capital depreciation & 0.20 \\
\hline \multicolumn{3}{|c|}{ Country A - Production } \\
\hline$\beta$ & Elasticity of ordinary tradables wrt effective labor & 0.64 \\
\hline$Q_{0}^{T, A}$ & Productivity parameter, ordinary tradables & 0.1213 \\
\hline$\varpi_{T}$ & Strength of Arrow-Romer externality, physical capital stock & 0.64 \\
\hline$v_{A}$ & Elasticity of labor productivity wrt drugs consumption & -0.018 \\
\hline$A_{0}^{A}$ & Productivity parameter, base labor productivity level & 14.59 \\
\hline$\chi$ & Elasticity of guns' production wrt tradable inputs & 0.5 \\
\hline$\omega$ & Production externality from economywide physical capital stock & 0.95 \\
\hline$A_{0}^{G}$ & $\begin{array}{l}\text { Time-invariant productivity parameter for guns' production } \\
\text { Country A - Government }\end{array}$ & 1.0 \\
\hline$\nu$ & Share of gov. consumption in domestically produced tradables & 0.340 \\
\hline$\tau_{L}$ & Labor income tax rate & 0.174 \\
\hline$\tau_{K}$ & Physical capital income tax rate & 0.350 \\
\hline$\tau_{G}$ & Taxation on guns' sales & 0.003 \\
\hline$z$ & Fraction of realizable value from confiscated drugs & 0.100 \\
\hline
\end{tabular}


Table 2

Benchmark Parameter Values, Country B

\begin{tabular}{clc}
\hline \hline Parameter & \multicolumn{1}{c}{ Cescription } & Value \\
\hline \hline & \multicolumn{1}{c}{ Country B - Individuals } \\
$\varsigma_{C B}$ & Elasticity of intertemporal substitution, ordinary goods & 0.667 \\
$\psi_{B}$ & Inverse of Frisch elasticity of labor supply & 1.5 \\
$\eta_{B}$ & Preference parameter, disutility of labor & 2.0 \\
$\Theta_{H B}$ & Parameter, efficiency of human capital investment & 0.156 \\
$\delta^{H B}$ & Formal/legal human capital depreciation rate & 0.05 \\
$\varrho$ & Share of domestically produced ordinary tradables & 0.8 \\
& $\quad$ Country B - Production & 0.6 \\
$\alpha$ & Elasticity of ordinary tradables wrt effective labor & 9.41 \\
$Q_{0}^{B}$ & Productivity parameter, ordinary tradables & 0.4 \\
$\phi_{1}$ & Strength of Arrow-Romer externality, formal human capital & \\
& $\quad$ Country B - Drug syndicate \& distribution & 1.291 \\
$A_{0}^{R}$ & Productivity parameter, drugs production & 0.076 \\
$\varphi$ & Elasticity of drugs production wrt drug-specific effective labor & 0.5 \\
$q$ & Uncertain drug-production capacity & 6.294 \\
$\kappa_{0}$ & Distribution cost parameter, drugs trade & 0.05 \\
$\rho$ & Elasticity of distr. cost wrt current-to-accumulated world drugs trade \\
\hline \hline
\end{tabular}


Table 3

Results Summary for Policy Experiments: Change in Transitory Growth Rates

(Absolute deviations from baseline)

A relaxation in the overall drug consumption climate in Country $A(\pi)$

\begin{tabular}{|c|c|c|c|c|c|c|c|}
\hline & Initial Values & Benchmark & $v_{A}=-0.072$ & $v_{A}=0.072$ & $\phi=0.1$ & $\rho=0.5$ & $\beta=0.3$ \\
\hline Growth of tradable output in Country A & 0.025 & -0.0083 & -0.0082 & -0.0085 & -0.0295 & -0.0101 & -0.0085 \\
\hline Growth of private consumption, Country A & 0.025 & 0.0020 & 0.0020 & 0.0020 & 0.0005 & 0.0021 & 0.0020 \\
\hline Growth of physical capital stock, Country A & 0.025 & -0.0083 & -0.0082 & -0.0085 & -0.0295 & -0.0101 & -0.0085 \\
\hline Growth of tradable output in Country B & 0.025 & 0.0000 & 0.0000 & 0.0000 & 0.0000 & 0.0000 & 0.0000 \\
\hline Growth of private consumption, Country B & 0.025 & -0.0083 & -0.0082 & -0.0085 & -0.0295 & -0.0101 & -0.0085 \\
\hline Growth of relative human capital stock, Country B & 0.000 & 0.0011 & 0.0011 & 0.0011 & 0.0003 & 0.0011 & 0.0011 \\
\hline Growth of current-period drug production & 0.025 & 0.0020 & 0.0020 & 0.0020 & 0.0005 & 0.0021 & 0.0020 \\
\hline Current-to-accumulated drug consumption ratio & 0.525 & -0.0011 & -0.0011 & -0.0011 & -0.0003 & -0.0011 & -0.0011 \\
\hline Price of drugs & 7.500 & 0.0007 & 0.0007 & 0.0007 & 0.0007 & 0.0071 & 0.0007 \\
\hline Growth of total guns production & 0.025 & -0.0083 & -0.0082 & -0.0085 & -0.0295 & -0.0101 & -0.0085 \\
\hline Price of guns & 4.120 & 0.0009 & 0.0009 & 0.0009 & 0.0020 & 0.0040 & 0.0009 \\
\hline \multicolumn{8}{|c|}{ A decrease in the drug production capacity in Country B (q) } \\
\hline & Initial Values & Benchmark & $V_{A}=-0.072$ & $v_{A}=0.072$ & $x=0.5$ & $\rho=0.5$ & $\alpha=0.3$ \\
\hline Growth of tradable output in Country A & 0.025 & 0.0157 & 0.0158 & 0.0154 & -0.0242 & 0.0130 & 0.0187 \\
\hline Growth of private consumption, Country A & 0.025 & 0.0030 & 0.0030 & 0.0031 & 0.0030 & 0.0032 & 0.0030 \\
\hline Growth of physical capital stock, Country A & 0.025 & 0.0157 & 0.0158 & 0.0154 & -0.0242 & 0.0130 & 0.0187 \\
\hline Growth of tradable output in Country B & 0.025 & 0.0000 & 0.0000 & 0.0000 & 0.0000 & 0.0000 & 0.0000 \\
\hline Growth of private consumption, Country B & 0.025 & 0.0157 & 0.0158 & 0.0154 & -0.0242 & 0.0130 & 0.0187 \\
\hline Growth of relative human capital stock, Country B & 0.000 & 0.0016 & 0.0016 & 0.0016 & 0.0016 & 0.0017 & 0.0016 \\
\hline Growth of current-period drug production & 0.025 & 0.0030 & 0.0030 & 0.0031 & 0.0030 & 0.0032 & 0.0030 \\
\hline Current-to-accumulated drug consumption ratio & 0.525 & -0.0016 & -0.0016 & -0.0016 & -0.0016 & -0.0017 & -0.0016 \\
\hline Price of drugs & 7.500 & 0.0010 & 0.0010 & 0.0010 & 0.0010 & 0.0106 & 0.0010 \\
\hline Growth of total guns production & 0.025 & 0.0157 & 0.0158 & 0.0154 & -0.0242 & 0.0130 & 0.0187 \\
\hline Price of guns & 4.120 & -0.0338 & -0.0338 & -0.0338 & -0.0338 & -0.0293 & -0.0338 \\
\hline
\end{tabular}

Note: All simulated policies represent a one percent shock from the initial value of the relevant policy arrangement.

Source: Authors' calculations.

Table 4

Results Summary for Policy Experiments: Change in Transitory Growth Rates (continue) (Absolute deviations from baseline)

An increase in the price mark-up shift parameter for drug distribution $\left(\mathbf{K}_{0}\right)$

\begin{tabular}{|c|c|c|c|c|c|c|c|}
\hline & Initial Values & Benchmark & $v_{A}=-0.072$ & $v_{A}=0.072$ & $\phi=0.1$ & $\rho=0.5$ & $\beta=0.3$ \\
\hline Growth of tradable output in Country A & 0.025 & -0.0181 & -0.0181 & -0.0182 & -0.0378 & -0.0191 & -0.0195 \\
\hline Growth of private consumption, Country A & 0.025 & 0.0011 & 0.0011 & 0.0012 & 0.0000 & 0.0012 & 0.0011 \\
\hline Growth of physical capital stock, Country A & 0.025 & -0.0181 & -0.0181 & -0.0182 & -0.0378 & -0.0191 & -0.0195 \\
\hline Growth of tradable output in Country B & 0.025 & 0.0000 & 0.0000 & 0.0000 & 0.0000 & 0.0000 & 0.0000 \\
\hline Growth of private consumption, Country B & 0.025 & -0.0181 & -0.0181 & -0.0182 & -0.0378 & -0.0191 & -0.0195 \\
\hline Growth of relative human capital stock, Country B & 0.000 & 0.0006 & 0.0006 & 0.0006 & 0.0000 & 0.0006 & 0.0006 \\
\hline Growth of current-period drug production & 0.025 & 0.0011 & 0.0011 & 0.0012 & 0.0000 & 0.0012 & 0.0011 \\
\hline Current-to-accumulated drug consumption ratio & 0.525 & -0.0006 & -0.0006 & -0.0006 & 0.0000 & -0.0006 & -0.0006 \\
\hline Price of drugs & 7.500 & 0.0654 & 0.0654 & 0.0654 & 0.0650 & 0.0690 & 0.0654 \\
\hline Growth of total guns production & 0.025 & -0.0181 & -0.0181 & -0.0182 & -0.0378 & -0.0191 & -0.0195 \\
\hline Price of guns & 4.120 & 0.0310 & 0.0310 & 0.0310 & 0.0165 & 0.0327 & 0.0310 \\
\hline \multicolumn{8}{|l|}{ An increase in the tax rate on guns sales $\left(\tau_{\sigma}\right)$} \\
\hline & Initial Values & Benchmark & $v_{A}=-0.072$ & $v_{A}=0.072$ & $x=0.5$ & $\rho=0.5$ & $\alpha=0.3$ \\
\hline Growth of tradable output in Country A & 0.025 & 0.0001 & 0.0001 & 0.0001 & -0.0001 & 0.0001 & 0.0001 \\
\hline Growth of private consumption, Country A & 0.025 & 0.0000 & 0.0000 & 0.0000 & 0.0000 & 0.0000 & 0.0000 \\
\hline Growth of physical capital stock, Country A & 0.025 & 0.0001 & 0.0001 & 0.0001 & -0.0001 & 0.0001 & 0.0001 \\
\hline Growth of tradable output in Country B & 0.025 & 0.0000 & 0.0000 & 0.0000 & 0.0000 & 0.0000 & 0.0000 \\
\hline Growth of private consumption, Country B & 0.025 & 0.0001 & 0.0001 & 0.0001 & -0.0001 & 0.0001 & 0.0001 \\
\hline Growth of relative human capital stock, Country B & 0.000 & 0.0000 & 0.0000 & 0.0000 & 0.0000 & 0.0000 & 0.0000 \\
\hline Growth of current-period drug production & 0.025 & 0.0000 & 0.0000 & 0.0000 & 0.0000 & 0.0000 & 0.0000 \\
\hline Current-to-accumulated drug consumption ratio & 0.525 & 0.0000 & 0.0000 & 0.0000 & 0.0000 & 0.0000 & 0.0000 \\
\hline Price of drugs & 7.500 & 0.0000 & 0.0000 & 0.0000 & 0.0000 & 0.0000 & 0.0000 \\
\hline Growth of total guns production & 0.025 & 0.0001 & 0.0001 & 0.0001 & -0.0001 & 0.0001 & 0.0001 \\
\hline Price of guns & 4.120 & 0.0000 & 0.0000 & 0.0000 & 0.0000 & 0.0000 & 0.0000 \\
\hline
\end{tabular}

Note: All simulated policies represent a one percent shock from the initial value of the relevant policy arrangement.

Source: Authors' calculations. 
Table 5

Drug Legalisation in Consumer Market - Long-run Growth effects in Country A:

Different value of $\phi$ and $\theta$

(Absolute deviations from baseline)

A relaxation in the overall drug consumption climate in Country A by one percent from initial value ( $\pi$ )

\begin{tabular}{c|cccccc}
\hline $\begin{array}{c}\text { Country A's consumption share of } \\
\text { domestically produced }(\boldsymbol{\theta})\end{array}$ & 0.455 & 0.555 & 0.655 & 0.755 & $\begin{array}{c}\mathbf{0 . 8 5 5} \\
\text { (Benchmark) }\end{array}$ \\
\hline Rate of (anti-)persistence $\boldsymbol{\phi}$ & & & & & \\
0.1 & -0.0002 & -0.0027 & -0.0074 & -0.0160 & -0.0295 \\
0.2 & 0.0010 & -0.0007 & -0.0035 & -0.0077 & -0.0127 & -0.0366 \\
0.3 & 0.0013 & -0.0002 & -0.0026 & -0.0060 & -0.0100 & -0.0114 \\
0.4 & 0.0014 & 0.0000 & -0.0022 & -0.0054 & -0.0089 & -0.0102 \\
0.5 (Benchmark) & 0.0015 & 0.0001 & -0.0020 & -0.0050 & -0.0083 & -0.0095 \\
0.6 & 0.0015 & 0.0002 & -0.0018 & -0.0048 & -0.0080 & -0.0091 \\
0.7 & 0.0015 & 0.0003 & -0.0018 & -0.0046 & -0.0078 & -0.0089 \\
0.8 & 0.0016 & 0.0003 & -0.0017 & -0.0045 & -0.0076 \\
0.9 & 0.0016 & 0.0003 & -0.0017 & -0.0045 & -0.0075 \\
& & & & & -0.0087 \\
\hline
\end{tabular}

Table 6

More Prohibitive Supply-side Policy - Growth effects on Private Consumption in Country B:

Different value of $\chi$ and $\varrho$

(Absolute deviations from baseline)

A decrease in the drug production capacity in Country B by one percent from initial probability value (q)

\begin{tabular}{|c|c|c|c|c|c|c|}
\hline $\begin{array}{r}\text { Country B' consumption share of } \\
\text { domestically produced }(\mathrm{e})\end{array}$ & 0.4 & 0.5 & 0.6 & 0.7 & $\begin{array}{c}0.8 \\
\text { (Benchmark) }\end{array}$ & 0.9 \\
\hline \multicolumn{7}{|l|}{$\begin{array}{l}\text { Elasticity of guns' production wrt tradable } \\
\text { inputs } \chi\end{array}$} \\
\hline 0.05 (Benchmark) & 0.0018 & 0.0053 & 0.0087 & 0.0122 & 0.0157 & 0.0191 \\
\hline 0.10 & 0.0037 & 0.0082 & 0.0132 & 0.0185 & 0.0245 & 0.0310 \\
\hline 0.15 & 0.0070 & 0.0142 & 0.0233 & 0.0353 & 0.0516 & 0.0752 \\
\hline 0.20 & 0.0132 & 0.0282 & 0.0552 & 0.0678 & 0.0742 & -0.0983 \\
\hline 0.25 & 0.0298 & 0.0657 & -0.0899 & -0.0870 & -0.0813 & -0.0720 \\
\hline 0.30 & 0.0723 & -0.1306 & -0.0691 & -0.0538 & -0.0469 & -0.0429 \\
\hline 0.35 & -0.0765 & -0.0481 & -0.0401 & -0.0364 & -0.0342 & -0.0327 \\
\hline 0.40 & -0.0387 & -0.0332 & -0.0308 & -0.0294 & -0.0285 & -0.0278 \\
\hline 0.45 & -0.0294 & -0.0275 & -0.0266 & -0.0260 & -0.0256 & -0.0253 \\
\hline $\begin{array}{l}\text { Structural break-point for } \chi, \text { for a given } \\
\text { consumption share of domestically- } \\
\text { produced in Country B: }\end{array}$ & 0.313 & 0.276 & 0.248 & 0.226 & 0.207 & 0.193 \\
\hline Indicative structural break-point for $\omega$ : & 0.687 & 0.724 & 0.752 & 0.774 & 0.793 & 0.807 \\
\hline
\end{tabular}


Figure 1

Guns, Drug Usage and GDP per Capita (2017)
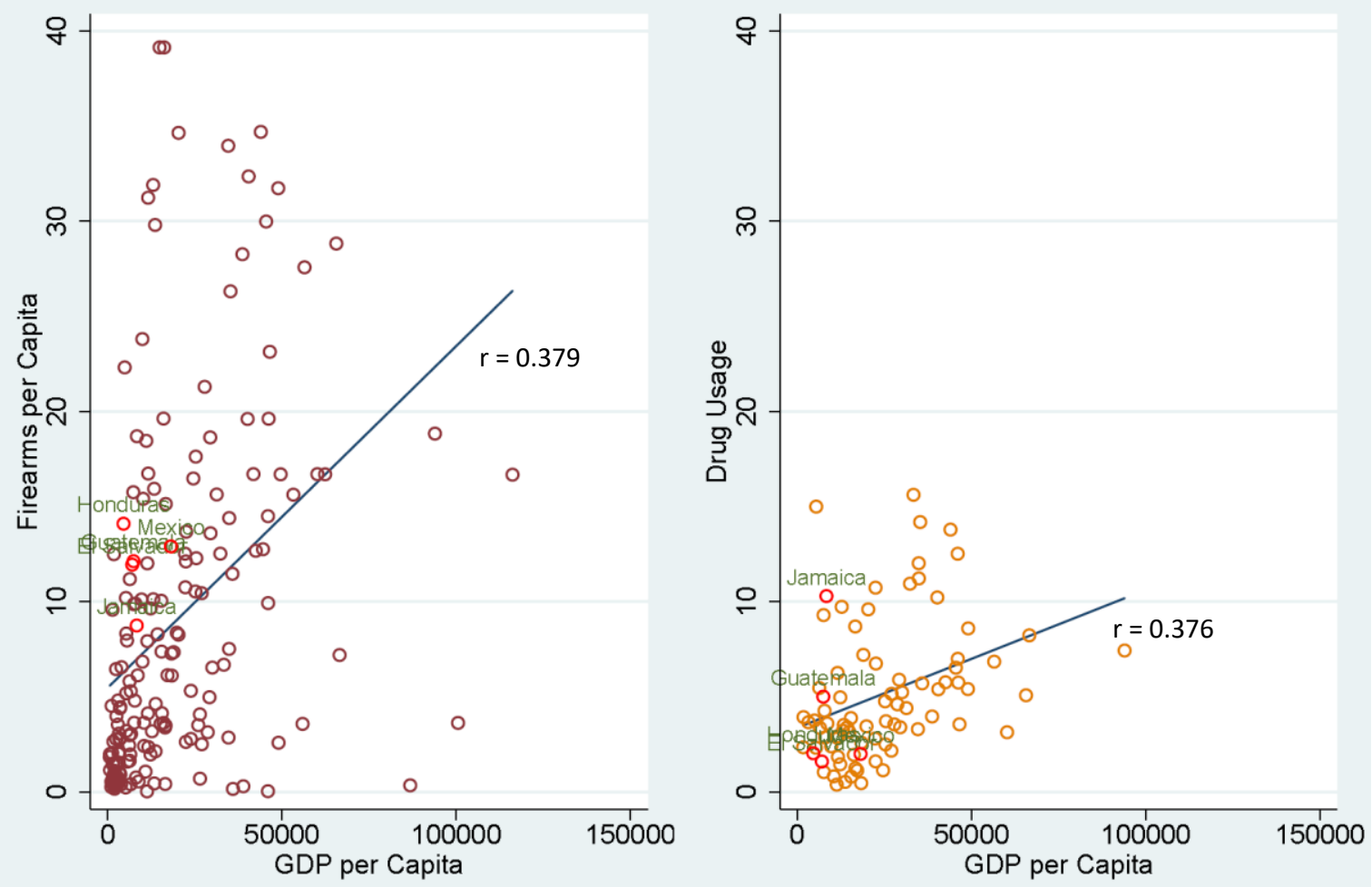

Source: Small Arms Survey 2017; UNODC Drug Statistics, World Development Indicators Note: The outlier observation of U.S.A is dropped from the sample in Figure 1.

Figure 2

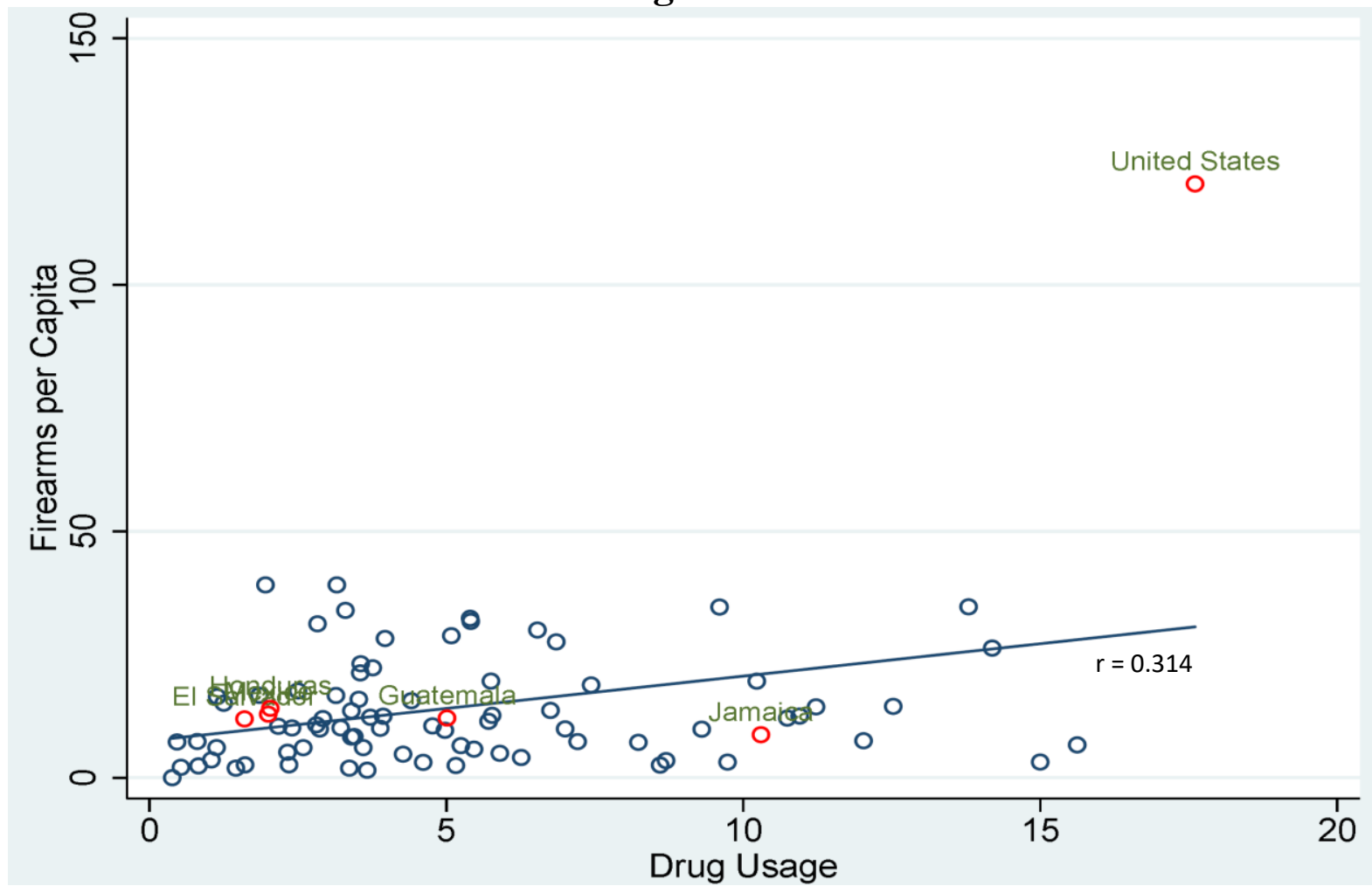

Source: Small Arms Survey 2017; UNODC Drug Statistics 